\title{
Şarj Edilebilir Nikel-Metal Hidrür (Ni-MH) Pillerinde Kullanılan Hidrojen Depolama Alaşımlarındaki SonGelişmeler
}

\author{
Nilüfer KÜÇÜKDEVECİ* \\ Nevşehir Hacı Bektaş Üniversitesi, Metalurji ve Malzeme Mühendisliği, Nevşehir
}

\begin{abstract}
$\ddot{O} \mathbf{z}$
Hidrojen depolama alaşımları şarj edilebilir Ni-MH pillerinin pratik uygulamaları için son zamanların çok geniş araştırma konusunu oluşturmaktadır. $\mathrm{Bu}$ derleme çalışmasında şarj edilebilir Ni-MH pilleri için $\mathrm{AB}_{5}$-tip, $\mathrm{AB}_{2}$-tip, TiV esaslı, R-Mg-Ni esaslı ve Mg-Ni esaslı hidrojen depolama alaşımlarının son yıllardaki gelişmeleri detaylı olarak anlatılmıştır. Son yıllarda gerçekleşen gelişmelere bağlı olarak var olan problemler ve ilgili sonuçlar sistematik olarak değerlendirilmiştir. Hidrojen depolama alaşımlarının, alaşım kompozisyonları, kristal yapıları ve elektrokimyasal özellikleri arasındaki bağlantı her bir alaşım çeşidi için tanımlanmış ve güç pilleri üzerinden analiz edilmiştir. Gelişen elektrikli araçlarda kullanımları için Ni-MH pillerindeki zorluklar bu çalışmada tartışılmıştır.
\end{abstract}

Anahtar kelimeler: Hidrojen Depolama, Ni-MH Piller, Elektrokimyasal Özellikler.

\section{Recent Developments of Hydrogen Storage Alloys Used in Nickel-Metal Hydride (Ni-MH) Rechargeable Batteries}

\begin{abstract}
Hydrogen storage alloys have been the subject of extensive research in recent years for practical applications of rechargeable $\mathrm{Ni}-\mathrm{MH}$ batteries. In this review, the developments of $\mathrm{AB}_{5}$-type, $\mathrm{AB}_{2}$-type, TiV-based, $\mathrm{R}-\mathrm{Mg}-\mathrm{Ni}$ based and $\mathrm{Mg}-\mathrm{Ni}$ based hydrogen storage alloys for rechargeable $\mathrm{Ni}-\mathrm{MH}$ batteries have been explained in detail in the last few years. Depending on the developments in the last few years, existing problems and related results have been evaluated systematically. The relationship between alloying compositions, crystal structures and electrochemical properties for each alloy type are also defined and analyzed with the emphasis on power batteries. Challenges in Ni-MH batteries for use in developing electric vehicles have been discussed in this study.
\end{abstract}

Keywords: Hydrogen Storage, Ni-MH Batteries, Electrochemical Properties.

\section{Giriş}

İnsanoğlu, gelişen sanayi ve teknoloji ile birlikte daha fazla enerjiye ihtiyaç duymaktadır. İhtiyaç duyulan enerjinin büyük miktarı fosil yakıtlar ile sağlanmaktadır. Ancak fosil yakıtlar belirli bir rezerve sahiptir. Fosil yakıtların yanmasıyla açığa çıkan zararlı gazlar ozon tabakasına ve doğaya büyük zararlar vermektedir. Bununla birlikte sera gazı etkisi yaratan $\mathrm{CO}_{2}$ gazı salınımı ile küresel 1sınmaya da neden olmaktadır. Fosil yakıtların yakın gelecekte tükenecek olması ve zararları nedeniyle alternatif enerji kaynakları araştırmaları giderek artmaktadır. Rüzgâr, güneş, jeotermal ve hidrojen vb. birçok temiz alternatif enerji kaynakları bulunmaktadır. Hidrojen enerji; nakledilmede pratik, çok kullanışlı, etkili, güvenli, çevreyle uyum içinde olmasından dolayı diğer enerji kaynakları arasında en iyi yakıt kaynağı olarak tanımlanabilir [1]. Hidrojenin oldukça ilgi görmesinin nedenleri;

1) Hidrojen; Yandığında çevreyi kirletici bir şey üretmediğinden (yandığında su buharı oluşur) temiz bir enerjidir.

2) Hidrojen; Evrende en fazla bulunan elementtir

\footnotetext{
*Sorumlu Yazar: niluferkucukdeveci@nevsehir.edu.tr Geliş Tarihi: 07.06.2018, Kabul Tarihi: 27.11.2018
} 
3) Hidrojen; En hafif ve birim kütle başına en zengin yakıttır.

4) Hidrojen; Kolaylıkla depolanabilir ve sudan üretilebilir.

5) Hidrojenin yanmasıyla üretilen 1 sınma enerjisi $(142,26 \mathrm{kj} / \mathrm{g})$, benzinin $(43,10-35,15 \mathrm{kj} / \mathrm{g})$, parafinin $(43,10-41,00 \mathrm{kj} / \mathrm{g})$, grafittin $(32,64 \mathrm{kj} / \mathrm{g})$, hint yağının $(39,33 \mathrm{kj} / \mathrm{g})$, kömürün $(32,50 \mathrm{kj} / \mathrm{g})$, ve tahtanın $(17,57 \mathrm{kj} / \mathrm{g})$ yanmasından elde edilen 1 sınma enerjilerinden daha yüksektir $[1,2]$.

6) Hidrojen; Doğrudan termal, mekanik ve elektriksel enerjiye dönüştürülebilir [1, 3-6].

7) Hidrojen; elektrik ile karşılaştırıldığında, nispeten uzun süreler depolanabilir [7]. maddeler halinde açıklanabilir.

Hidrojenin enerji olarak kullanılabilmesi için hidrojenin üretilmesi ve depolanması en önemli iki problemdir. Bu makalede, hidrojenin depolama yöntemlerinden biri olan katı halde depolama konusu esas alınmıştır.

Hidrojenin enerji olarak kullanılması ile ilgili çoğu araştırma, hidrojen depolamanın mobil uygulamaları için yapılmaktadır. Hidrojen gaz, sıvı ve katı halde depolanabilmektedir. Hidrojenin depolanmasında klasik metotlar; doğal gaz formda basınçlı tanklarda ve kriyojenik sıcaklıklarda sıvı hale getirerek özel yalıtımlı tanklarda depolanmasıdır. Hidrojenin gaz formda depolanması en eski bilinen, ucuz ve basit bir yöntemdir. Hidrojen tanklarında hidrojen gazı 35 ve $70 \mathrm{MPa}$ basınç altında depolanmaktadır. Bu metot düşük hacimsel yoğunluğa ve patlama riskine sahip olduğundan kullanımı sinırlıdir $[1,6,8]$.

Sıvı halde hidrojen 21,2 K'de kriyojenik tanklarda depolanabilmektedir. Ancak soğutma ve basınç altında depolama işlemi enerji gerektirir. Bu nedenle hidrojenin sıvılaştırılması ve depolanma sırasında depolanan enerjinin yaklaşı \%30'unun kaybolmasına neden olur.

Bazı metaller hidrojenle birleşerek metal hidrür oluşturabilmektedir. Normal sıcaklık ve basınç değerlerinde hidrojen metal yüzeyine ilk adsorbe, daha sonra metal içerisine difüze olur ve en son metal hidrür oluşumu ile bir katı içerisine hidrojen depolanabilmektedir. Metal hidrürlerin hidrojen depolama yoğunluğu 6,5 hidrojen atom $/ \mathrm{cm}^{3}$, gaz halde hidrojen depolama yoğunluğu 0,99 hidrojen atom $/ \mathrm{cm}^{3}$ ve sıv1 halde hidrojen depolama yoğunluğu 4,2 hidrojen atom/ $/ \mathrm{cm}^{3}$ 'tür. Bu sonuçlara göre metal hidrürler yüksek hacimsel yoğunluk kadar mobil uygulamalar için güvenli ve hacim yönünden etkin depolama sağlamaktadır [9].

\section{Nikel-Metal Hidrür Piller}

Yapılan son çalışmalara göre hidrojenin metal hidrür formunda depolanması ve taşınabilir cihazlarda kullanılması büyük önem teşkil etmektedir. Özellikle geliştirilen elektrikli araçlarda artan temiz ve yenilenebilir yakıt ihtiyacı bu çalışmaların daha fazla yapılmasına neden olmaktadır $[1-5,8,9]$. Bu bağlamda şarj edilebilir piller örneğin kurşun-asit pilleri, nikel-kadmiyum pilleri, nikel-metal hidrür pilleri ve lityum-iyon pilleri elektrikli araçlarda enerji taşıyıcı olarak pratik uygulamalar için geliştirilmektedir. Şekil 1 ve Tablo 1'de gösterildiği gibi Lityum-iyon pilleri Ni-MH (Nikel Metal Hidrür) pillere göre nispeten daha fazla enerji taşımasına karşın, güvenlik açısından oldukça tehlikelidir. Ni-MH pilleri, taşınabilir el aletleri ve Hibrid elektrikli araçlar için yüksek güç kapasitesi, aşırı şarj/deşarja karşı toleransa, çevreye uyum ve güvenlik özelliklerine sahiptir [10].

Ni-MH pilleri aşağıda belirtilen bazı dezavantajlara sahiptir.

1) Tekrarlayan deşarj sonrasında özellikle yüksek yük yoğunluklarında, Ni-MH pillerinin performansları düşmeye başlayarak döngü ömürleri 200-300 çevrime kadar düşer.

2) Lityum iyon pilleri ile karşılaştırıldığında birim fiyat ağırlık oranına göre daha pahalıdırlar.

3) Yüksek sıcaklıklarda kapasitesi ve güç yoğunluğu düşer.

4) Kendiliğinden deşarj oranı yüksektir $[11,12]$. 


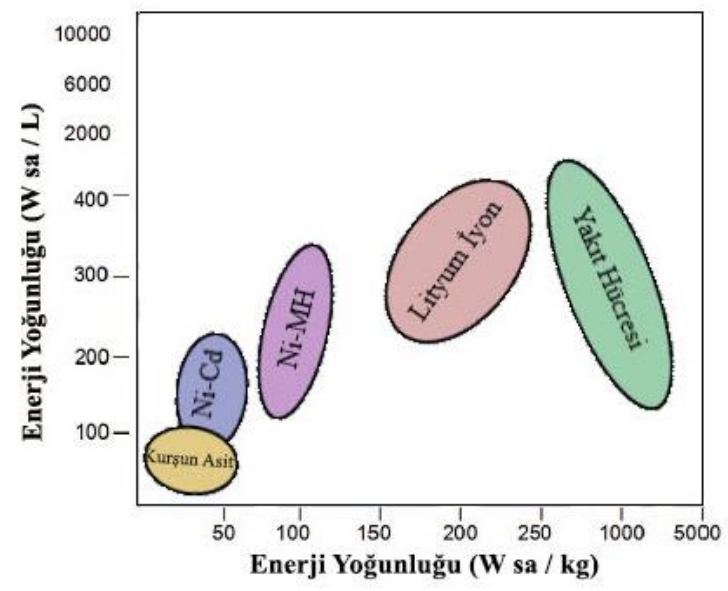

Şekil 1. Farklı pil teknolojilerinin hacimsel ve gravimetrik enerji yoğunluğu ve bazı hidrojen depolama malzemeleri açısından karşılaştırılması [10]

Tablo 1. Elektrikli araç uygulamaları için kullanılan şarj edilebilir piller [13]

\begin{tabular}{|c|c|c|c|c|c|}
\hline Pil & Çevresel özelliği & $\begin{array}{c}\text { Nominal gerilim } \\
(\mathbf{V})\end{array}$ & Maliyet(\$/Wa) & $\begin{array}{c}\text { Spesifik enerji } \\
(\mathbf{W s a} / \mathbf{k g})\end{array}$ & Çevrim ömrü \\
\hline Kurşun-Asit & Toksik & 2,0 & $0,1-0,3$ & $20-35$ & $100-500$ \\
\hline Ni-Cd & Toksik & 1,2 & $0,5-1,5$ & $30-50$ & 1000 \\
\hline Ni-MH & Düşük Toksik & 1,2 & 1,0 & $60-120$ & 500 \\
\hline Li-iyon & Tehlikeli & $1,5-3,9$ & $0,2-0,3$ & $115-265$ & $400-1200$ \\
\hline
\end{tabular}

Ni-MH pili, negatif elektrot metal hidrür, pozitif elektrot $\mathrm{Ni}(\mathrm{OH})_{2}$ ve alkalin elektrolit $(\mathrm{KOH})$ 'ten oluşmaktadır. Elektrokimyasal hidrojen depolamada basitçe suyun ayrışması ile hidrojen element halinde elde edilmektedir (Reaksiyon 1). Hidrojen elementi ilk önce metal (negatif elektrot) yüzeyine adsorbe olur ve daha sonra metalin içine difüze olarak hidrojen absorbsiyonu ile hidrür oluşumu gerçekleşir. Elektrokimyasal hidrojen depolamada şarj/deşarj da gerçekleşen reaksiyonlar şematik olarak Şekil 2'de gösterilmektedir. Bir Ni/MH pilinde Şarj/deşarj sürecinde gerçekleşen elektrokimyasal reaksiyonlar aşağıda verilmektedir [10, 14-16]

Pozitif elektrotta şarj sürecinde; $\mathrm{Ni}(\mathrm{OH})_{2}, \mathrm{NiOOH}$ yükseltgenir (Reaksiyon 1).

$\mathrm{Ni}(\mathrm{OH})_{2}+\mathrm{OH}^{-} \underset{\text { ŞarJ }}{\stackrel{\text { Desarj }}{\longrightarrow}} \mathrm{NiOOH}+\mathrm{H}_{2} \mathrm{O}+e^{-}$

Negatif elektrotta şarj sürecinde; $M$ hidrojen depolama alaşımıdır. Suyun indirgenme reaksiyonu gerçekleşerek çözelti-katı ara yüzeyinde $\mathrm{H}_{\text {ads }} v e \mathrm{OH}^{-}$iyonu oluşur. Bu reaksiyon ile element halindeki Hidrojen Metal yüzeyine adsorbe olur (Reaksiyon 2).

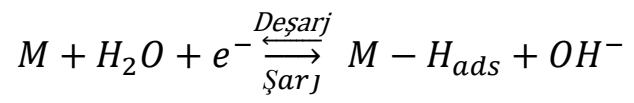

Hidrojenin alaşım içerisine difüzyonu gerçekleşir. Adsorbe olan hidrojen absorbe olarak katıçözelti fazı M-H $\mathrm{Hbs}_{\mathrm{ab}(\alpha)}$ oluşmaktadır (Reaksiyon 3) (Şekil 2 b).

$M-H_{\text {ads }}=M-H_{a b s(\alpha)}$ 
b).

Artan hidrojen konsantrasyonu ile $\alpha$ fazı bir hidrür fazına dönüşmektedir (Reaksiyon 4, Şekil 2

$M-H_{a b s(\alpha)}=M-H_{a b s(\beta)}$

Deşarj sürecinde, şarj sürecinde gerçekleşen reaksiyonların tam tersi gerçekleşir.

Toplam Reaksiyon;

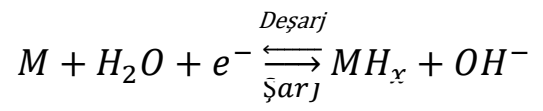
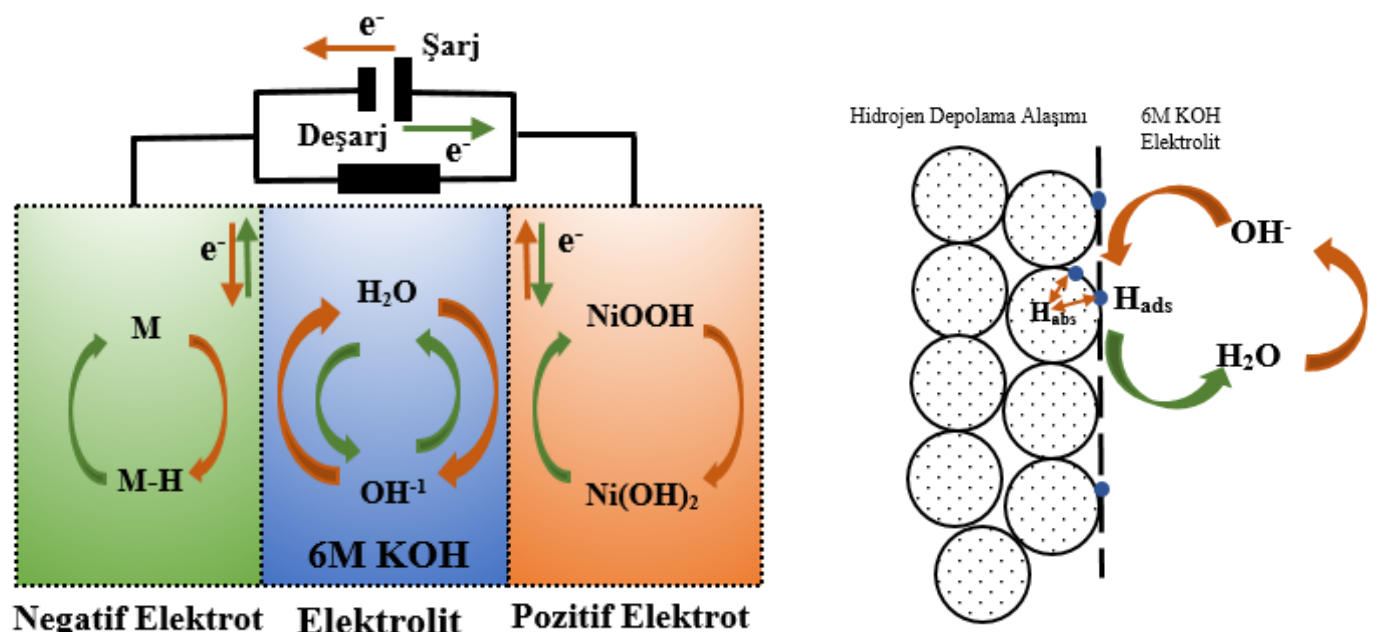

Negatif Elektrot Elektrolit Pozitif Elektrot

Şekil 2. a)Bir Ni-MH pilindemeydanagelenŞarj/Deşarjreaksiyonsüreçlerininşematikgörünümüve

b)Elektrokimyasalyük transfer reaksiyonu vasıtasıyla oluşan hidrür oluşumu / ayrışma sürecinin şematik gösterimi [14]

Ni-MH pilin aşırı şarj veya deşarj olduğunda pozitif ve negatif elektrotta gerçekleşen süreç aşağıdaki reaksiyonlarla açıklanabilir;

Aşırı şarj süresince;

Pozitif elektrotta; $4 \mathrm{OH}^{-} \rightarrow 2 \mathrm{H}_{2} \mathrm{O}+\mathrm{O}_{2}+4 e^{-}$

Negatif elektrotta; $2 \mathrm{H}_{2} \mathrm{O}+\mathrm{O}_{2}+4 e^{-} \rightarrow 4 \mathrm{OH}^{-}$

Toplam reaksiyon; $4 \mathrm{MH}+\mathrm{O}_{2} \rightarrow 4 \mathrm{M}+2 \mathrm{H}_{2} \mathrm{O}$

Aşırı deşarj sürecinde;

Pozitif elektrotta; $2 \mathrm{H}_{2} \mathrm{O}+2 e^{-} \rightarrow \mathrm{H}_{2}+2 \mathrm{OH}^{-}$

Negatif elektrotta $\mathrm{H}_{2}+2 \mathrm{OH}^{-} \rightarrow 2 \mathrm{H}_{2} \mathrm{O}+2 e^{-}$

Toplam reaksiyon; $x H_{2}+2 M \rightarrow 2 M H_{x}$

Genel olarak, negatif elektrotun kapasitesi pozitif elektrotun kapasitesinden daha yüksek ayarlanır. Pozitif elektrottan üretilen oksijen aşırı şarj boyunca metal hidrür (MH) elektrotun yüzeyinde indirgenebilir. Aşırı deşarj sürecinde indirgenme ürünü hidrojen $\mathrm{MH}$ tarafından absorbe edilmektedir. 
Böylece aşırı şarj/deşarj boyunca Ni-MH pilleri mükemmel tolerans edebilme özelliği gösterirler $[10,18]$.

Birçok araştırmada yüksek basınç koşullarında Nikel Metal hidrür pillerinde katodun ( $\mathrm{NiOOH})$ hidrojene karşı yüksek kimyasal reaktivitesi olduğundan, yüksek oranda kendiliğinden deşarj gösterdiği bulunmuştur. Aşağıda belirtilen reaksiyon pilin açık devre koşullarında katotta gerçekleşebilir.

Pozitif elektrot; $\mathrm{NiOOH}+1 / 2 \mathrm{H}_{2}=\mathrm{Ni}(\mathrm{OH})_{2}$

Kendiliğinden deşarj, pozitif elektrotta yukarıda belirtilen reaksiyon gerçekleşmesi sonucunda her iki elektrotun yavaşça bozunmasına ve empürite iyonlarının çözelti içerisinde anot katot arasında mekik dokuması gibi etkilere neden olur [20].

Ni-MH pillerin prensiplerine ve çalışma koşullarına göre bir hidrojen depolama elektrot alaşımı aşağıdaki özelliklere sahip olmalıdır.

1) Yüksek enerji yoğunluğuna

2) Mükemmel güç yoğunluğuna

3) Hidrojen adsorbsiyon ve desorbsiyonu için iyi elektrokimyasal katalize

4) Elektrokimyasal enerji depolama özelliklerinde kararlılığa

5) Uzun şarj/deşarj çevrim ömrüne

6) Geniş aralıkta çalışma sicaklığına

7) Ucuz ve elektronik araçlar için taşınabilir ve kolay uygulanabilirliğe

8) Çevreye zararlı olmayan ve geri dönüştürülebilir malzemeler vb. gibi özelliklere sahip olmalıdır $[10,14,18]$.

Ni-MH pillerinin elektrokimyasal performansları; spesifik kapasitelerine, aktivasyon özelliklerine, yüksek hız deşarj kabiliyetlerine, çevrimsel kararlılıklarına ve elektrokimyasal kinetik parametrelerine göre farklılık gösterir [1]. Bu özellikler elektrotun iç özelliklerine (alaşım kompozisyonu ve yapısal özellikleri) bağlı olarak değişir. $\mathrm{AB}_{5}$-tip, $\mathrm{AB}_{2}$-tip, Mg-esaslı alaşımlar, Ti-V esaslı alaşımlar ve RE-Mg-Ni esaslı süperlatis alaşımları Ni-MH piller için anot malzemesi olarak elektrokimyasal özelliklerini (enerji yoğunluğu, yüksek hız deşarj edilebilirliği ve çevrim ömrü vb.) geliştirmek için yoğun çalışmalar yapılmaktadır [1-17].

\section{Ni-MH Pilleri İçin Hidrojen Depolama Alaşımları}

Farklı stokiyometre ile birleşen iki farklı A ve B metal elementi hidrojen depolama elektrot alaşımları için kullanılmaktadır. Elektrot alaşımlarında A bileşeni (periyodik tabloda 3. veya 4. sütünda bulunan elementtir) kararlı hidrür oluşumu için gereklidir. B bileşeni (periyodik tabloda 5-10 sütünlarında bulunan geçiş elementidir) ise şarj/deşarj sırasında elektrotun kataliz olmasını böylece şarj/deşarj kinetik özelliklerini geliştirmesinde, hidrojen adsorbsiyon/desorpsiyon denge basıncını arzu edilen şekilde değiştirmede, elektrotun kimyasal kararlığını geliştirmede rol oynamaktadır [13].

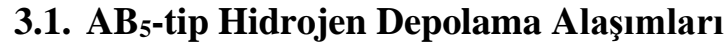

$\mathrm{AB}_{5}$-tip hidrojen depolama alaşımları genellikle A nadir toprak elementi $\mathrm{B}$ ise $\mathrm{Ni}, \mathrm{Co}, \mathrm{Mn}$ vb. geçiş elementinden oluşmaktadır. $\mathrm{AB}_{5}$-tip hidrojen depolama alaşımları, $\mathrm{CaCu}_{5}$-tip hekzagonal kristal yapısına sahiptirler (Şekil 3). 


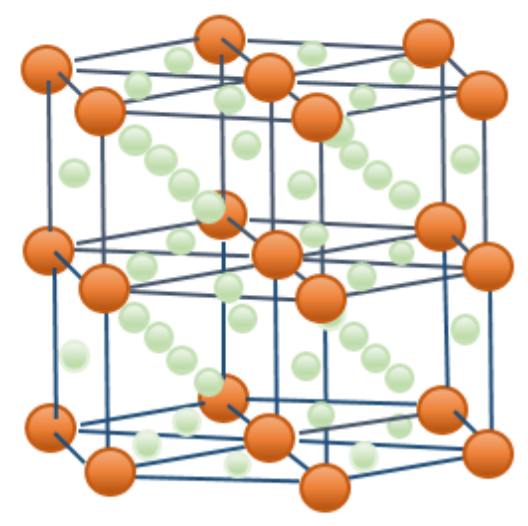

La

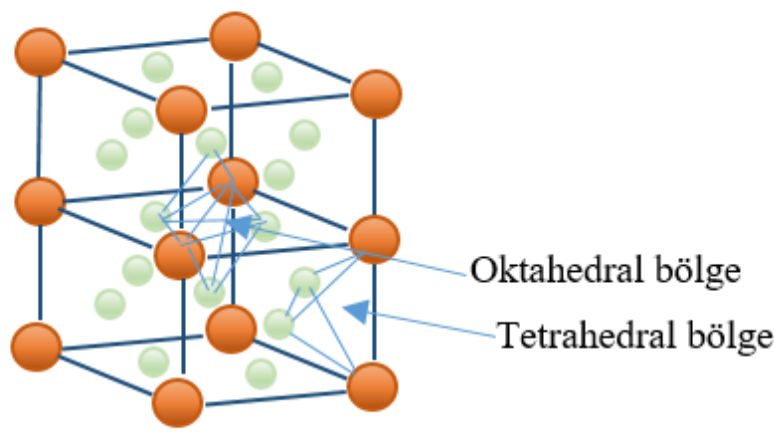

$\mathrm{Ni}$

Şekil 3. $\mathrm{LaNi}_{5}$ hidrojen depolama alaşımının kristal yapısı [10]

Pratik uygulamalarında $\mathrm{LaNi}_{5}$ alaşımları düşük çevrim kararlılığı gösterirler. Bunun nedeni elektrot-elektorlit ara yüzünde oluşan yüzey oksidasyonu $\left(\mathrm{La}_{2} \mathrm{O}_{3}\right)$ ve tekrarlayan hidrojen adsorbsiyonu ve desorpsiyonu sırasında partikül boyutunun küçülerek ufalanmasıdır (Pulverisation) [21,22]. Nikel yerine kısmen Co elementinin ilavesinin gerçekleştirilmesiyle üretilen $\mathrm{LaNi}_{5}$ hidrojen depolama alaşımının şarj/deşarj çevrim ömrü artmaktadır. Böylece Ni-MH pillerinin ticarileşmesinin kapıları açılmıştır [21]. $\mathrm{AB}_{5}$-tip hidrojen depolama alaşımlarının elektrokimyasal depolama kapasitelerini artırmak için, A ve B elementi yerine kısmen başka elementler ilavesi ile modifiye edilmektedir. $\mathrm{AB}_{5}$ tip hidrojen depolama alaşımlarının depolama kapasiteleri yaklaşık 250-320 mA sa g-1' $\operatorname{dır}$ (Tablo 2) [10, $14,21]$.

Tablo 2. Bazı $\mathrm{AB}_{5}$ tiphidrojen depolama alaşımlarının hidrojen depolama kapasiteleri [21]

\begin{tabular}{|c|c|}
\hline Kompozisyon & $\begin{array}{c}\text { Hidrojen depolama } \\
\text { kapasitesi mA sa g-1 }\end{array}$ \\
\hline $\mathrm{LaNi}_{5}$ & 387 \\
\hline $\mathrm{LaNi}_{4,7} \mathrm{Al}_{0,3}$ & 370 \\
\hline $\mathrm{LaNi}_{4,25} \mathrm{Co}_{0,75}$ & 386 \\
\hline $\mathrm{LaNi}_{3} \mathrm{Co}_{2}$ & 334 \\
\hline $\mathrm{LaNi}_{4} \mathrm{Cu}$ & 334 \\
\hline $\mathrm{LaNi}_{4} \mathrm{Fe}$ & 327 \\
\hline $\mathrm{LaNi}_{4,6} \mathrm{Mn}_{0,4}$ & 386 \\
\hline $\mathrm{LaNi}_{4} \mathrm{Mn}$ & 364 \\
\hline $\mathrm{LaNi}_{4,5} \mathrm{Sn}_{0,5}$ & 304 \\
\hline $\mathrm{LaNi}_{3,55} \mathrm{Mn}_{0,4} \mathrm{Al}_{0,3} \mathrm{Co}_{0,75}$ & 334 \\
\hline $\mathrm{MmNi}_{3,55} \mathrm{Co}_{0,75} \mathrm{Mn}_{0,4} \mathrm{Al}_{0,3}$ & 332 \\
\hline
\end{tabular}

$\mathrm{LaNi}_{5}$ alaşımlarında elektrokimyasal depolama özelliklerini geliştirmek için Ni yerine kısmi olarak Sn, Co, Al, Mn, Fe ve Si; La yerine ise kısmi olarak Ce, Pr, Nd elementleri ilave edilmektedir. Nikel yerine kısmi olarak ilave edilen elementlerle oluşturulan alaşımların çevrim ömrü, $\mathrm{Mn}<\mathrm{Ni}<\mathrm{Cu}$ $<\mathrm{Cr}<\mathrm{Al}<\mathrm{Co}$ elementlerin sıralamasına göre gelişmektedir [23]. Buradan anlaşılacağı üzere optimum 
çevrim ömrünü geliştiren Co elementidir. LaNi ${ }_{5}$ hidrojen depolama alaşımına kısmi olarak ilave edilen elementlerin hidrojen depolama alaşımının elektrokimyasal özelliklerine etkileri Tablo 3 'te özetlenerek verilmiştir.

Tablo 3. Elementlerin $\mathrm{AB}_{5}$ tip hidrojen depolama alaşımlarının üzerindeki etkileri

\begin{tabular}{|c|c|}
\hline Element & $\mathbf{A B}_{5}$ tip hidrojen alaşımlarına elementlerin etkileri \\
\hline $\operatorname{Al}[24-27]$ & $\begin{array}{l}\text { Korozyon direncini artırır } \\
\text { Daha az ufalanma(pulverization) } \\
\text { Çevrim kararlılığını artırır. } \\
\text { Aktivasyon özelliklerini artırır. }\end{array}$ \\
\hline $\mathrm{Co}[28-31]$ & $\begin{array}{l}\text { Hidrojen depolama sırasında hacimsel genişlemeyi azaltır } \\
\text { (Pulverization azalır) } \\
\text { Hidrürleme/dehidrürleme basıncını düşürür. } \\
\text { Aktivasyonu artırır. } \\
\text { Çevrim ömrü artar }\end{array}$ \\
\hline $\mathrm{Fe}[10,32-34]$ & $\begin{array}{l}\text { Korozyon direncini artırır } \\
\text { Elektrokimyasalreaksiyonun kinetik özelliklerini geliştirir. } \\
\text { Yüzey aktivasyonunu artırır. }\end{array}$ \\
\hline $\operatorname{Mn}[13,35,36]$ & $\begin{array}{l}\text { Elektrokimyasal reaksiyonun kinetik özelliklerini geliştirir. } \\
\text { Hidrojen depolama kapasitesini artırır. } \\
\text { Aktivasyonu artırır. } \\
\text { Çevrim Kararlılığını artırır. }\end{array}$ \\
\hline $\operatorname{Sn}[14,37,38]$ & $\begin{array}{l}\text { Elektrokimyasalreaksiyonun kinetik özelliklerini geliştirir. } \\
\text { Aktivasyonu artırır. } \\
\text { Çevrim kararlılığı artar } \\
\text { Çevrim ömrü artar. }\end{array}$ \\
\hline Si [39] & $\begin{array}{l}\text { Al, Mn göre elektrokimyasal kinetik özelliklerini daha iyi geliştirir. } \\
\text { Aktivasyon özelliklerini artırır. }\end{array}$ \\
\hline $\mathrm{Ce}[40,41]$ & $\begin{array}{l}\text { Kafes kristal yapısını değiştirmez. } \\
\text { Kafes parametresi artar. } \\
\text { Korozyon direncini artırır. } \\
\text { Çevrim ömrünü artırır. } \\
\text { Hidrojen depolama kapasitesini artırır } \\
\text { Yüksek hız deşarj edilebilirliği artırır. }\end{array}$ \\
\hline $\mathrm{Nd}, \operatorname{Pr}[10,41]$ & $\begin{array}{l}\text { Hidrojen depolama kapasitesini artırır } \\
\text { Yüksek hız deşarj edilebilirliği artırır } \\
\text { Aktivasyon özelliklerini artırır. }\end{array}$ \\
\hline
\end{tabular}

Kobalt, Pr, Nd elementleri çevrim kararlılığını ve hidrojen depolama kapasitesini artırdığından ticari Ni-MH pillerinde elektrot malzemelerinde kullanılmaktadır. Elektrot malzemelerin ticari şarj edilebilir pillerde rekabet edilebilmesi için üretim maliyetleri azaltılmalıdır. Maliyeti yüksek olan elementlerin kullanımının azaltılması veya yüksek maliyetli bu elementler yerine maliyeti düşük başka elementlerin kullanılması ile üretim maliyetini düşürmek mümkündür. Bunun sonucu olarak yüksek performanslı bir pil için $\mathrm{Co} / \mathrm{Pr} / \mathrm{Nd}$ elementlerini içermeyen ve/veya bu elementler bakımından düşük içerikli hidrojen depolama alaşımları geliştirilmesi son yıllarda yapılan çalışmalarda büyük önem arz etmektedir [42-48]. Nikel-Metal Hidrür pillerinde Lantan yerine hidrür oluşturabilen ve çevrim kararlığını artıran $\mathrm{La}, \mathrm{Ce}, \mathrm{Nd}, \mathrm{Pr}$ vb. elementlerden oluşan çok bileşenli maliyeti düşük $\mathrm{Mm}$ (misch metal) alaşımı kullanılmaktadır. Lantanca zengin Mm ve seryumca zengin Mm hidrojen depolama alaşımları şeklinde iki grupta araştırmalar devam etmektedir [14, 49, 50]. Düşük Co içeriğine sahip $\mathrm{MmNi}_{3,55} \mathrm{Co}_{0,75} \mathrm{Mn}_{0,4} \mathrm{Al}_{0,3}(\mathrm{Mm}=62 \% \mathrm{La}, 27 \% \mathrm{Ce}, 0,8 \% \mathrm{Nd}, 0,3 \% \mathrm{Pr})$ hidrojen depolama alaşımı ticari pillerde yaygın olarak kullanılmaktadır $[43,51]$. Yao ve arkadaşları düşük Co içeriğine sahip $\mathrm{LaNi}_{4.5} \mathrm{Co}_{0.25} \mathrm{Al}_{0.25}$ alaşımını ark ergitme yöntemi ile belirli hızlarda su vererek üretmişler ve maksimum deşarj kapasitesini 312,5 mA sa g-1 olarak bulmuşlardır [49]. Ming ve arkadaşları $\mathrm{LaNi}_{5}$ tip hidrojen depolama alaşımlarını Ni yerine kısmi olarak $\mathrm{Mn}$ ve Co ilavesiyle modifiye ederek $\mathrm{LaNi}_{3.2 \mathrm{-}-\mathrm{X}} \mathrm{Mn}_{0,3} \mathrm{Co}_{\mathrm{x}}(\mathrm{x}$ $=0,2 \sim 0,8)$ hidrojen depolama alaşımını üretmişler, $\mathrm{x}=0,2$ olan alaşımın maksimum deşarj kapasitesini

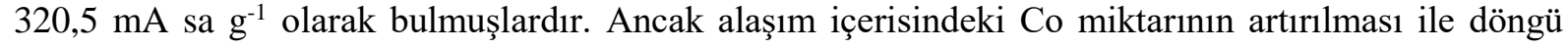
kararlılığının artığı belirtilmiştir [52]. Hibrid elektrik araçları için çevrim yöntemi ve kısa D-boyutlu kapalı hücrenin güç verimi deneyleri ile $\mathrm{Mm}_{0,96} \mathrm{Mg}_{0,04} \mathrm{Ni}_{4,175} \mathrm{Co}_{0,325} \mathrm{Mn}_{0,4} \mathrm{Al}_{0,3}$ alaşımının, 25000 çevrim sonra başlangıç güç ve deşarj kapasitesi değerlerinin \%80'ini koruduğu bulunmuştur. Bu sonuç hibrid elektrikli aracının $100000 \mathrm{~km}$ yol almasına eşdeğerdir. Üretilen bu alaşım yüksek güç, uzun çevrim ömrü ve düşük maliyete sahip olduğundan Ni-MH pilleri için önemli bir gelişmedir. Düşük Co içeriğine sahip $\mathrm{AB}_{5}$ esaslı hidrojen depolama alaşımlarına Mg ilavesi ile üretilen alaşımın düşük maliyete, uzun 
çevrim ömrüne ve yüksek güce sahip olmasından dolayı Hibrid elektrikli araçlarında kullanılabileceğini göstermektedir [53]. Ancak literatürde çok sayıda yapılan araştırmalarda LaNis-tip hidrojen depolama alaşımlarının deşarj kapasiteleri yaklaşık 300-330 mA sa g-1 arasında değişmektedir. Bu bağlamda $\mathrm{LaNi}_{5}$ tip hidrojen depolama alaşımları, Ni-MH pillerinin artan enerji yoğunluğu ihtiyacı için yeterli değildir. $\mathrm{Bu}$ nedenle yüksek enerji-güç yoğunluğuna sahip yeni elektrot alaşımlarının geliştirilmesine ihtiyaç duyulmaktadir.

\section{2. $\mathbf{A B}_{2}$-tip Hidrojen Depolama Alaşımları}

$\mathrm{AB}_{2}$ tip hidrojen depolama alaşımları daha yüksek enerji yoğunluğuna sahip olduklarından Ni-MH pil uygulamaları için ikinci nesil alaşımlar olarak tanımlanabilirler. $\mathrm{AB}_{2}$ tip alaşımlar $\mathrm{A} ; \mathrm{Zr}$ veya $\mathrm{Ti}, \mathrm{B} ; \mathrm{V}$, $\mathrm{Cr}$ veya $\mathrm{Mn}$ ikili bileşimlerinden oluşur. $\mathrm{AB}_{2}$ tip alaşımlar hekzagonal $\mathrm{C} 14\left(\mathrm{MgZn}_{2}\right)$, kübik $\mathrm{C} 15$ $\left(\mathrm{MgCu}_{2}\right)$ ve hekzagonal C36 $\left(\mathrm{MgNi}_{2}\right)$ fazlarından oluşurlar ve bunlar Lave faz yapılarıdır. Bu fazlar kafes içerisinde atomların dolum düzenlerine bağlıdır ve atom yarıçapları oranı $R_{A} / R_{B}=1,225$ ' dir. Lave fazlarından C14 ve C15 fazları iyi hidrojen absorbe etme özelliği gösterirken, C36 fazı zayıf hidrojen absorbisyonu göstermektedir $[18,54] . \mathrm{AB}_{2}$ tip hidrojen depolama alaşımlarının elektrokimyasal performanslarını artırmak için A ve B yerine kısmen başka elementlerin ilavesi gerçekleştirilmektedir. $\mathrm{Bu}$ nedenle $\mathrm{AB}_{2}$-tip hidrojen depolama alaşımları çok bileşenli alaşımlardır ve $\mathrm{Ti}, \mathrm{Zr}, \mathrm{V}, \mathrm{Ni}, \mathrm{Cr}, \mathrm{Co}$, $\mathrm{Mn}, \mathrm{Al}, \mathrm{Fe}$ vb. elementleri içermektedirler. Bu alaşımların deşarj kapasiteleri $370-440 \mathrm{~mA} \mathrm{sa} \mathrm{g^{-1 }}$ arasında değişmektedir [55]. $\mathrm{AB}_{2}$ tip hidrojen depolama alaşımlarının hidrojen depolama kapasiteleri ve $\mathrm{AB}_{5}$ tip hidrojen depolama alaşımlarına göre oldukça yüksektir. Tablo 4 'te $\mathrm{AB}_{2}$-tip hidrojen depolama alaşımlarına ilave edilen elementlerin elektrokimyasal hidrojen depolama özelliklerine etkileri özetlenerek verilmiştir [34]. $\mathrm{Ti}_{0,98} \mathrm{Zr}_{0,02} \mathrm{~V}_{0,43} \mathrm{Fe}_{0,09} \mathrm{Cr}_{0,05} \mathrm{Mn}_{1,5}$ alaşımı 2000 şarj/deşarj çevrimi sonrasında deşarj kapasitesinde \% 5'den daha az azalma meydana geldiğinden, alaşım oldukça yüksek döngü kararlılı̆̆ına sahiptir [56]. Ovonic pil şirketi tarafından anot elektrot alaşımı olarak geliştirilen $\mathrm{V}_{5} \mathrm{Ti}_{9} \mathrm{Zr}_{26,2} \mathrm{Ni}_{38} \mathrm{Cr}_{3,5} \mathrm{Co}_{1,5} \mathrm{Mn}_{15,6} \mathrm{Al}_{0,4} \mathrm{Sn}_{0,8}$ alaşımın enerji yoğunluğu $1057 \mathrm{Wsa} / \mathrm{kg}$ 'dır ve 1000 çevrimde mükemmel kararlılığa sahiptir [10]. Ancak $\mathrm{AB}_{2}$ tip hidrojen alaşımlarının aktivasyonu için uzun süre gerekmektedir. $\mathrm{Bu}$ nedenle $\mathrm{AB}_{2}$ tip alaşımlarının aktivasyonunu hızlandırmak için günümüzde çok sayıda araştırma yapılmaktadır. Üretilen hidrojen alaşımlarını mekanik olarak öğütmek [57], hidrojen depolama alaşımını belli bir süre, belli bir sıcaklıktaki $\mathrm{KOH}$ (Potasyum hidroksit) veya $\mathrm{KOH}$ çözeltisine farklı kimyasallar koyarak (KHB4, HF vb.) [58, 59, 60] içerisinde daldırarak bekletmek gibi yöntemler aktivasyon hızını artırmak için günümüzde yapılan araştırmaları oluşturmaktadır. Tan ve arkadaşlarının yaptıkları araştırmaya göre kaynayan $\mathrm{KOH}$ çözeltisi içerisinde 80 dakika bekletilen $\left(\mathrm{Ti}_{0,36} \mathrm{Zr}_{0,64}\right)\left(\mathrm{V}_{0,15} \mathrm{Ni}_{0,58} \mathrm{Mn}_{0,20} \mathrm{Cr}_{0,07}\right)_{2}$ hidrojen depolama alaşımının ikinci şarj/deşarj çevriminden sonra maksimum deşarj kapasitesine ulaştığı, yapılan ön işlem ile $\mathrm{AB}_{2}$ tip hidrojen depolama alaşımının aktivasyon hızını artırdığını bulmuşlardır [60]. $\mathrm{AB}_{2}$ tip hidrojen depolama alaşımlarına göre $\left(\mathrm{LaNi}_{5}\right.$ esaslı hidrojen depolama alaşımlarına göre maliyeti düşük olmasına rağmen) maliyeti daha düşük, ağırlıkça daha hafif olan, bu özelliklerin yanı sıra çevrim kararlılığı ve enerji güç yoğunluğu daha yüksek olan günümüzdeki elektrikli araçlarda kullanılmak üzere Ni-MH ticari pilleri için anot elektrot alaşımı geliştirilmesi gerekmektedir. 
Tablo 4. Lave faz esaslı (C14 faz yapısına sahip) hidrojen depolama alaşımlarına kısmen ilave edilen elementlerin etkileri [34]

\begin{tabular}{|c|c|}
\hline Element & $\mathbf{A B}_{2}$ tip hidrojen depolama alaşımlarına elementlerin etkileri \\
\hline $\mathrm{Al}$ & $\begin{array}{c}\text { Al difüzyonu ve yüzey reaktivitesini geliştirir. } \\
\text { Co ile birlikte kullanıldığında elektrokimyasal performansını geliştirir. }\end{array}$ \\
\hline B & $\begin{array}{l}\text { B düşük-sıcaklık performansını ve hızlı deşarj edilebilirliği artırır. } \\
\text { Ancak çevrim ömrünü, kapasiteyi ve şarj tutma özelliklerinin düşürür. }\end{array}$ \\
\hline $\mathrm{C}$ & $\begin{array}{c}\text { C şarj tutma özelliğini ve hızlı deşarj edilebilirliği artırır. } \\
\text { Düşük sıcaklık performansını (kapasite ve çevrim ömrü) düşürür. }\end{array}$ \\
\hline Co & $\begin{array}{c}\text { Co kolay yüzey aktivasyonu sağlar. } \\
\text { Deşarj kapasitesini düşürür. } \\
\text { Şarj tutma özelliğini ve çevrim ömrünü geliştirir. } \\
\text { Hızlı deşarj edilebilirliği azaltır. }\end{array}$ \\
\hline $\mathrm{Cr}$ & $\begin{array}{l}\text { Cr şarj tutma özelliğini geliştirir. } \\
\text { Hızlı deşarj edilebilirliği azaltır. }\end{array}$ \\
\hline Mo & $\begin{array}{l}\text { Hızlı şarj edilebilirliği geliştirir. } \\
\text { Şarj tutma özelliğini geliştirir. } \\
\text { Düşük sıcaklık performansını geliştirir. } \\
\text { Çevrim ömrünü geliştirir. }\end{array}$ \\
\hline $\mathrm{Cu}$ & $\begin{array}{c}\text { Cu aktivasyonu kolaylaştırır. } \\
\text { Deşarj kapasitesini artırır. } \\
\text { Ancak hızlı deşarj edilebilirliği düşürür. }\end{array}$ \\
\hline $\mathrm{Fe}$ & $\begin{array}{c}\text { Fe aktivasyonu kolaylaştırır. } \\
\text { Toplam elektrokimyasal kapasiteyi artırır. } \\
\text { Etkili yüzey reaksiyonu alanı sağlar. } \\
\text { Ancak hızlı deşarj edilebilirliği düşürür. } \\
\text { Düşük-sıcaklık performansı azaltır. }\end{array}$ \\
\hline Gd & $\begin{array}{l}\text { Gd düşük-sıcaklık performansını geliştirir. } \\
\text { Ancak hızlı deşarj edilebilirliği düşürür. } \\
\text { Deşarj kapasitesini düşürür. } \\
\text { Şarj tutma özelliğini ve çevrim ömrünü düşürür. }\end{array}$ \\
\hline $\mathrm{La}$ & $\begin{array}{l}\text { La deşarj kapasitesini geliştirir. } \\
\text { Hızlı deşarj edilebilirliği geliştirir. } \\
\text { Düşük sıcaklık performansını düşür. }\end{array}$ \\
\hline $\mathrm{Mg}$ & $\begin{array}{l}\text { Mg şarj tutma özelliğini geliştirir. } \\
\text { Deşarj kapasitesini düşürür. } \\
\text { Düşük sıcaklık performansını düşürür. } \\
\text { Çevrim ömrünü düşürür. }\end{array}$ \\
\hline Mn & $\begin{array}{l}\text { Mn deşarj kapasitesini gelişritir. } \\
\text { Aktivasyonu kolaylaştırır. } \\
\text { Çevrim ömrünü düşürür. }\end{array}$ \\
\hline $\mathrm{Ni}$ & $\begin{array}{c}\text { Ni çevrim ömrünü geliştirir. } \\
\text { Hızlı deşarj edilebilirliği artırır. } \\
\text { Kapasiteyi düşürür. }\end{array}$ \\
\hline $\mathrm{Pt}$ & $\begin{array}{c}\text { Pt kapasiteyi geliştirir. } \\
\text { Hızlı deşarj edilebilirliği geliştirir. }\end{array}$ \\
\hline $\mathrm{Si}$ & $\begin{array}{l}\text { Atomca \%1 Si ilavesi hızlı deşarj edilebilirliği artırır. } \\
\text { Düşük-sıcaklık performansını geliştirir. }\end{array}$ \\
\hline $\mathrm{Sn}$ & $\begin{array}{c}\text { Sn şarj tutma özelliğini geliştirir. } \\
\text { Hızlı deşarj edilebilirliği azaltır. } \\
\text { Çevrim özelliği azaltır. }\end{array}$ \\
\hline $\mathrm{Ti}$ & $\begin{array}{c}\text { Ti aktivasyonu kolaylaştırır. } \\
\text { Hızlı deşarj edilebilirliği artırır. }\end{array}$ \\
\hline $\mathrm{V}$ & $\begin{array}{l}\text { V kapasiteyi artırır. } \\
\text { Şarj tutma özelliğini düşürür. } \\
\text { Hızlı deşarj edilebilirliği düşürür. }\end{array}$ \\
\hline $\mathrm{Y}$ & $\begin{array}{c}\text { Y aktivasyonu geliştirir. } \\
\text { Hızlı deşarj edilebilirliği geliştirir. } \\
\text { Düşük sıcaklık performansını geliştirir. }\end{array}$ \\
\hline $\mathrm{Zr}$ & Zr kapasiteyi artırır. \\
\hline
\end{tabular}




\subsection{Ti-V Esaslı Çok Fazlı Alaşımlar}

TiV esaslı hidrojen depolama alaşımlarının deşarj kapasiteleri oldukça yüksektir. Geleneksel metal hidrürlerin hidrojen depolama kapasiteleri ağırlıkça \%1,8, TiV esaslı hidrojen depolama alaşımlarının ise hidrojen depolama kapasiteleri ağırlıkça \%4'tür ve bu nedenle hidrojen depolama uygulamaları için potansiyel malzemelerdir [57]. Ancak bu alaşımların hidrojen absorbiyon sırasında yavaş aktivasyona ve kinetiğe sahip olmalarının yanı sıra, Ti-V esaslı hidrojen depolama alaşımları düşük çevrim kararlılığına ve yüksek üretim maliyetlerine sahiplerdir. Bu dezavantajları gidermek için Ti ve $\mathrm{V}$ elementleri yerine kısmen $\mathrm{Zr}, \mathrm{Cr}$, Fe ve $\mathrm{Mn}$ gibi başka elementlerin ilavesi ile alaşım kompozisyonu değiştirilmektedir. $\mathrm{Bu}$ elementlerin ilavesi ile vanadyum esaslı katı çözelti yanında C14 faz yapısı oluşmaktadır [62-66]. Vanadyum esaslı katı çözelti faz yapısı temel hidrojen absorbe eden faz yapısıdır. C14 faz yapısı hidrojen absorbe etmesinin yanında vanadyum esaslı fazın elektrokimyasal hidrojen absorbsiyonu ve desorbsiyonu sürecinde bir katalizör görevi görmektedir [67, 68].

Tsukahara ve arkadaşları ark ergitme yöntemiyle ürettikleri $\mathrm{TiV}_{3} \mathrm{Ni}_{0,56}$ hidrojen depolama alaşımının maksimum deşarj kapasitesi $420 \mathrm{~mA}$ sa $\mathrm{g}^{-1}$ olarak bulmuşlar ancak çevrim kararlılı̆̆ının olmadığını, yetmiş yedinci çevrimde deşarj kapasitesini tamamen kaybettiğini belirtmişlerdir [58]. Yu ve arkadaşları Ti-30V-15Cr-15Mn alaşımını mekanik alaşımlama ile üretildiğinde maksimum deşarj

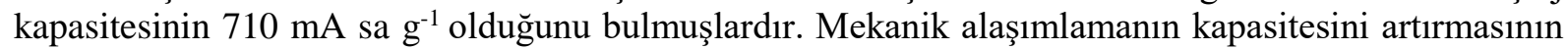
yanı sıra çevrim kararlılığını da artırdığını belirtmişlerdir [69]. Bu sonuçlar Ni-MH ticari pilleri için umut vericidir. Ancak zayıf kinetikleri ve zayıf çevrim kararlılıkları pratikte kullanımlarını olanaksız kılmaktadır.

Ti-V esaslı hidrojen depolama alaşımlarının kapasitelerinin hızla düşmesinin iki nedeni vardır. Birincisi şarj/deşarj çevrimi sürecinde alaşım partiküllerinin ufalanması, ikincisi ise alaşımın yüzeyinin oksidasyonudur [14]. Hidrojen depolama performansını geliştirmek için en etkili yöntem daha önceden bahsedildiği gibi alaşımın kompozisyonunu değiştirmektir. $\mathrm{Bu}$ nedenle farklı elementler kullanılmaktadır. TiV esaslı hidrojen depolama alaşımlarının kompozisyonunu değiştirmek için ve optimum alaşım kompozisyonu elde etmek için kullanılan elementler Ti, Zr, Cr, Fe, Mn, Al, Co ve Ni'dir [70-74]. Ti-V esaslı hidrojen alaşımlarında Ti, Zr ve $\mathrm{V}$ hidrojen absorbsiyonunu gerçekleştiren elementlerdir. $\mathrm{Bu}$ alaşımlarda kullanılan nikel indirgenme reaksiyonu için katalitik aktivite sağlamaktadır, ayrıca Co ve Mn ise yüzey aktivitesini geliştirmektedir. Krom, alüminyum ve demir elementleri ilave edildiğinde ise Ti-V esaslı hidrojen depolama alaşımlarının korozyon direncini artırmaktadır [14]. Nadir toprak elementlerinin (La, Y, Ce, Pr, Nd vb.) TiV esasl hidrojen depolama alaşımlarına ilavesinin hidrojen depolama performansı üzerindeki etkileri Gao ve arkadaşları tarafından araştırılmıştır. Ti-V esaslı hidrojen depolama alaşımlarına kısmen ilave edilen Y elementi ile daha iyi bir performans ve deşarj kapasitesi (360 $\mathrm{mA} \mathrm{sa}^{-1}$ ) elde etmişlerdir [75].

$\mathrm{Bu}$ alaşımların pratik uygulamalarının gerçekleştirilebilmesi için daha fazla araştırmaya ihtiyaç duyulmaktadır.

\subsection{R(Rare earth, nadir toprak)-Mg-Ni-Esashı Hidrojen Depolama Alaşımlar}

$\mathrm{AB}_{5}$ tip nadir toprak elementi içeren alaşımları günümüzde başarıyla ticari pillerde kullanılmaktadır. Ancak artan enerji güç yoğunluğu ihtiyacını karşılayamamaktadır [10-21, 23-44]. $A B_{3}$ ve ya $A_{2} B_{7}$ tip nadir toprak-magnezyum esaslı hidrojen depolama alaşımları yeni geliştirilen alaşımlardır ve yüksek deşarj kapasiteye sahip olmasının yanında yüksek hızla deşarj edilebilirlik özelliğine sahiplerdir. $\mathrm{Bu}$ nedenle yüksek enerji ve güç yoğunluğuna sahip Ni-MH pillerinin geliştirilmesinde gelecek nesil negatif elektrot malzemeleri olarak düşünülmektedir. Yüksek enerji ve güç yoğunluğuna sahip olmalarına rağmen, yapısal karalılıklarının olmaması bu alaşımların gelişimini sınırlamaktadır. Bu malzemelerin pratikte kullanılabilmelerini sağlamak için pek çok araştırma yapılmaktadır.

$\mathrm{R}-\mathrm{Mg}$-Ni tip hidrojen depolama alaşımlarının alaşım kompozisyonuna ve yapısal özelliklerine bağlı olan deşarj kapasitesi, aktivasyon, çevrim kararlılığı, yüksek hız deşarj edilebilirlik ve elektrokimyasal kinetik parametreler çok uzun süredir araştırılmaktadır. R-Mg-Ni esaslı hidrojen depolama alaşımlarının elektrokimyasal özelliklerine bu alaşımların modifikasyonu için kullanılan elementlerin bireysel etkileri detaylı olarak Tablo 5'te verilmektedir [17]. 
Tablo 5. R-Mg-Ni esaslı alaşımlarının elektrokimyasal özellikleri üzerinde elementlerin etkileri [17]

\begin{tabular}{|c|c|}
\hline Element & Re-Mg-Ni-tip hidrojen depolama alaşımlarına elementlerin etkileri \\
\hline $\mathrm{La}$ & $\begin{array}{c}\text { Birim hücre hacmini artırır. } \\
\text { Plato özelliklerini geliştirir. } \\
\text { Deşarj kapasitesini, kolay aktivasyon olma özelliğini ve hızlı deşarj edilebilirliğini artırır. } \\
\text { Birim hücrenin genişleme oranı fazla ve Lantan korozyona uğrdığından zayıf çevrim kararlığına sebep olur. }\end{array}$ \\
\hline $\mathrm{Mg}$ & $\begin{array}{c}\text { Hidrürlerin amorfizasyonunu engeller. } \\
\text { Hidrürün kararlılığını ve birim hücre hacmini azaltır. } \\
\text { Deşarj kapasitesini, hızlı deşarj edilebilirliğini ve çevrim kararlılığın artırır. }\end{array}$ \\
\hline $\mathrm{Ce}$ & $\begin{array}{l}\text { Birim hücre hacmini azaltır. } \\
\text { Hidrojen absorbsiyonu ve desorbsiyonunun plato basıncını düşürür. } \\
\text { Hidrojen depolama kapasitesini düşürür. } \\
\text { Deşarj kapasitesini azaltır. } \\
\text { Çevrim kararlılı̆̆ını geliştirir ve hızlı deşarj edilebilirliği artırır. }\end{array}$ \\
\hline Pr ve Nd & $\begin{array}{l}\text { Fazların hücre hacimlerini ve kafes parametrelerini azaltır. } \\
\text { Hidrojen desorpsiyonunun basınç platosunu artırır. } \\
\text { Maksimumu deşarj kapasitesini düşürür. } \\
\text { Çevrim kararlılığını geliştirir ve hızlı deşarj edilebilirliği artırır. }\end{array}$ \\
\hline $\mathrm{Zr}$ & $\begin{array}{c}\text { Hücre hacimlerini düşürür. } \\
\text { Maksimumu deşarj kapasitesini düşürür. } \\
\text { Hızlı deşarj edilebilirliği artırır. }\end{array}$ \\
\hline Co & $\begin{array}{l}\text { Kafes parametrelerini ve birim hücre hacimlerini artırır. } \\
\text { Hidrojen absorbsiyonu ve desorbsiyonunu histerizisini ve plato basıncını düşürür. } \\
\text { Hidrojen depolama kapasitesini düşürür. } \\
\text { Birim hücre hacim değişimini azalttığından çevrim kararlılı̆̆ını etkili bir şekilde artırır ve yüzey } \\
\text { pasivasyonunun artıırı. } \\
\text { Elektrokimyasal kinetiğini artırır. }\end{array}$ \\
\hline $\mathrm{Mn}$ & $\begin{array}{l}\text { Kafes parametrelerini ve birim hücre hacimlerini artırır. } \\
\mathrm{LaNi}_{5} \text { faz oluşumunu kolaylaştırır. } \\
\text { Plato basıncını düşürür. } \\
\text { Maksimumu deşarj kapasitesini ve çevrim kararlılığını artırır. } \\
\text { Elektrokimyasal kinetiğini artırır. }\end{array}$ \\
\hline $\mathrm{Al}$ & $\begin{array}{l}\text { Kafes parametrelerini ve birim hücre hacimlerini artırır. } \\
\text { Plato basıncını düşürür, plato eğimini artırır. } \\
\text { Hidrojen kapasitesini düşürür. } \\
\text { Kalın Oksit filmi oluşturmasından dolayı(La ve Mg korozyonunu önler) çevrim kararlılığı önemli derecede } \\
\text { artırır. } \\
\text { Maksimum deşarj kapasitesini ve yüksek hız deşarj edilebilirliği düşürür. }\end{array}$ \\
\hline $\mathrm{Fe}$ ve $\mathrm{Cu}$ & $\begin{array}{l}\text { Deşarj potansiyelini, yüksek hız deşarj edilebilirliği ve deşarj kapasitesini düşürür. } \\
\text { Çevrim kararlılığını geliştirir. }\end{array}$ \\
\hline $\mathrm{Cr}$ & $\begin{array}{l}\text { Birim hücre hacmini artırır. } \\
\text { Deşarj kapasitesini düşürür. } \\
\text { Çevrim kararlılığını geliştirir. } \\
\text { Yüksek hız deşarj edilebilirliği azaltır. }\end{array}$ \\
\hline W ve Mo & $\begin{array}{c}\text { Maksimum deşarjı düşürür. } \\
\text { Yüksek hız deşarj edilebilirliği ve çevrim kararlılığını artırır. } \\
\text { İyonik ve elektronik iletkenliği artırır. }\end{array}$ \\
\hline
\end{tabular}


R-Mg-Ni alaşımlarının üretilmesinde ark ergitme [76-78], hızlı katılaştırma [79-82], toz sinterleme [82,83], mekanik alaşımlama [84-86], elektrodeoksidasyon [87, 88] vb. gibi birçok yöntem bulunmaktadır. Yapısal özellikleri kullanılan üretim tekniğine göre ve alaşımın yapısal özelliklerine bağlı olarak elektrokimyasal hidrojen depolama özellikleri değişmektedir.

Chen ve arkadaşları $\mathrm{LaCaMg}(\mathrm{NiM})_{9}(\mathrm{M}=\mathrm{Al}, \mathrm{Mn})$ alaşımlarının maksimum deşarj kapasitesinin

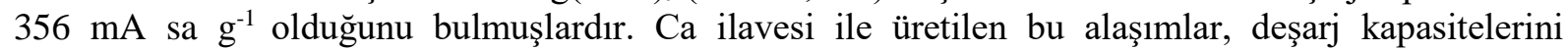
koruyamamaktadır [89]. Zhang ve arkadaşları $\mathrm{La}_{0,7} \mathrm{Mg}_{0,3} \mathrm{Ni}_{3,5-\mathrm{x}}\left(\mathrm{Al}_{0,5} \mathrm{Mo}_{0,5}\right)_{\mathrm{x}}(\mathrm{x}=0,6)$ ark ergitme yöntemi ile üretilen hidrojen depolama alaşımının maksimum deşarj kapasitesi $\left(397,6 \mathrm{~mA} \mathrm{sa} \mathrm{g}^{-1}\right)$ ticari $\mathrm{AB}_{5}$ tip alaşımlarından oldukça yüksektir. Buna rağmen ticari pillere göre çevrim kararlılığını çok daha az koruyabilmektedir. Ancak Zhang ve arkadaşlarının sentezlediği $\mathrm{La}_{1,5} \mathrm{Mg}_{0,5} \mathrm{Ni}_{5,2} \mathrm{Co}_{1,8}$ elektrot alaşımının deşarj kapasitesi 405,69 mA sa g ${ }^{-1}$ dır [90]. Pan ve arkadaşları $\mathrm{La}_{0,7} \mathrm{Mg}_{0,3} \mathrm{Ni}_{2,8} \mathrm{Co}_{0,5}$ elektrot alaşımına $1123 \mathrm{~K}$ 'de 8 saat süre 1 sıl işlem uyguladıklarında, uygulanan 1 sıl işlemin yapı ve kompozisyonu homojenleştirmesi nedeniyle alaşımın deşarj kapasitesinin $414 \mathrm{~mA} \mathrm{sa} \mathrm{g}^{-1}$ yükseldiğini, daha uzun çevrim kararlılı̆̆ına sahip olduğunu bulmuşlardır [91]. Yapılan aynı çalışmada daha uzun süreli ve daha yüksek sıcaklıklarda yapılan isıl işlemin faz miktarındaki önemli değişimlere neden olması nedeniyle deşarj kapasitesini kötüleştirdiği belirtilmiştir. R-Mg-Ni alaşımlarına Al ve Co elementlerinin ilavesi önemli gelişme sağlamasına rağmen bu alaşımların üretim maliyetleri endüstride kullanımlarına engel teşkil etmektedir. Bu yüzden endüstride kullanımı düşük maliyete sahip olarak üretilen optimize R-Mg-Ni tip alaşımlar (düşük kobalt içeriğine sahip ya da kobalt içermeyen) yüksek deşarj kapasiteye, uzun çevrim ömrüne ve iyi kinetik özelliklerine sahip olmalarına rağmen Ni-MH pillerinde kullanımları için yeterli özelliklere sahip değillerdir.

\subsection{Mg Esaslı Hidrojen Depolama Alaşımları}

Son yıllarda yapılan çalışmalarda Nikel-Metal Hidrür pillerinde elektrot malzemelerinde kullanılmak üzere gravimetrik enerji yoğunluğu yüksek alaşımlar araştırılmaktadır. Hidrojeni adsorbe etme özelliğine sahip 48 element vardır, ancak kullanımları için gravimetrik enerji yoğunlukları yeterli değildir. Hidrojen depolama özelliğine sahip elementlerden biri olan magnezyumun gravimetrik depolama kapasitesi yaklaşık $2200 \mathrm{~mA} \mathrm{sa} \mathrm{g}{ }^{-1}$ (ağırlıkça \%7,6 hidrojen)dır [92]. Ayrıca $\mathrm{Mg}_{2} \mathrm{Ni}_{\text {hidrojen }}$ depolama alaşımının teorik deşarj kapasitesi $1080 \mathrm{~mA} \mathrm{sa} \mathrm{g}^{-1}$ ' dır [93]. Bu nedenle elektronik araçlarda $\mathrm{Ni}-\mathrm{MH}$ pillerinin kullanılması için, anot malzemesi olarak Magnezyum esaslı hidrojen depolama alaşımları oldukça umut vaat etmektedir. Ancak Mg-esaslı hidrojen depolama alaşımları zayıf hidrojen adsorbsiyon/desorbsiyon kinetiğine sahip olduklarından ve alkalin çözelti içerisinde yapısal kararlılıkların koruyamadıklarından dolayı pratik uygulamaları oldukça sınırlıdır [94,95]. Magnezyum'un ve Nikel'in yerine kısmi olarak başka elementlerin katılması ile alaşım kompozisyonun değiştirilmesi Mg-Ni alaşımlarının hidrojen depolama performansını geliştirmek için yapılan en yaygın yöntemdir.

MgNi esaslı alaşımların mekanik alaşımlamayla sentezlenerek üretilmesi ile hidrojen depolama kapasiteleri arttığı bilinmektedir. Ancak çevrim kararlılıkları ve hidrojen adsorbsiyon/desorbsiyon kinetikleri istenilen düzeyde değildir. MgNi alaşımlarının zayıf çevrim kararlılıklarına sahip olmasının nedeni alaşım yüzeyinde alkalin çözelti içerisinde şarj/deşarj çevrimi süresince $\mathrm{Mg}(\mathrm{OH})_{2}$ tabakasının oluşması ve şarj/deşarj sürecinde bu tabakanın difüzyonu engellemesidir. Bu nedenle MgNi esaslı alaşımların hidrojen depolama performanslarını geliştirmek için dört veya beş elementle alaşım kompozisyonu değiştirilerek modifiye edilmektedir. Anık ve arkadaşlarının yaptığı çalışmada MgNi esaslı alaşımlar Ti, Al, Zr, Pd ve Co elementleri ilave edilerek mekanik alaşımlama ile sentezlenmiştir. $\mathrm{Bu}$ çalışmada üretilen $\mathrm{Mg}_{0.80} \mathrm{Ti}_{0.15} \mathrm{Al}_{0.05} \mathrm{Zr}_{0.05} \mathrm{Ni}_{0.95}$ alaşımının deşarj kapasitesi $420 \mathrm{~mA}$ sa g ${ }^{-1}$ ve 20 şarj/deşarj çevrimi süresince kapasite koruma oranı $\% 90$ olarak bulunmuştur (Tablo 6). Bu çalışmaya göre alaşım yüzeyinde Alüminyum ve Alüminyum oksit, Titanyum ve Titanyum oksit, alaşım yüzeyinde oluşan $\mathrm{Mg}(\mathrm{OH})_{2}$ tabakasının kararlılığını azaltmaktadır. Zirkonyum elementi ise atom boyutunun büyük olması nedeniyle alaşım yapısında hidrojen elementi için ekstra yer açmasına neden olmakta ve hidrojen depolama kapasitesini artırmaktadır. Ancak Pd ve Co elementlerinin MgNi esaslı alaşımlarının hidrojen depolama kapasitesi üzerine önemli bir etkisi olmadığı düşünülmektedir [96, 97]. 
Tablo 6.MgNi esaslı alaşımlara $\mathrm{Ti}, \mathrm{Al}, \mathrm{Zr}$, Pd ve Co elementleri sistematik olarak ilave edilerek mekanik alaşımlama ile sentezlenen alaşımların hidrojen depolama kapasiteleri ve koruma oranları [97]

\begin{tabular}{|c|c|c|c|}
\hline $\begin{array}{l}\text { MgNi Esaslı Hidrojen } \\
\text { Depolama Alaşımı }\end{array}$ & $\begin{array}{c}\text { 1. Şarj/Deşarj } \\
\text { Kapasitesi(mAs/g) }\end{array}$ & $\begin{array}{c}\text { 20. Şarj/Deşarj } \\
\text { Kapasitesi(mAsa/g) }\end{array}$ & $\begin{array}{c}\text { \% Kapasite } \\
\text { Koruma } \\
\text { Oranı }\end{array}$ \\
\hline $\mathrm{Mg}_{0,80} \mathrm{Ti}_{0,15} \mathrm{Al}_{0,10} \mathrm{Ni}_{0,95}$ & 324 & 301 & $\% 93$ \\
\hline $\mathrm{Mg}_{0,80} \mathrm{Ti}_{0,15} \mathrm{Al}_{0,05} \mathrm{Pd}_{0,05} \mathrm{Ni}_{0,95}$ & 326 & 299 & $\% 92$ \\
\hline $\mathrm{Mg}_{0,80} \mathrm{Ti}_{0,15} \mathrm{Al}_{0,05} \mathrm{Zr}_{0,05} \mathrm{Ni}_{0,95}$ & 417 & 378 & $\% 91$ \\
\hline $\mathrm{Mg}_{0,80} \mathrm{Ti}_{0,15} \mathrm{Al}_{0,05} \mathrm{Co}_{0,05} \mathrm{Ni}_{0,95}$ & 376 & 322 & $\% 86$ \\
\hline $\mathrm{Mg}_{0,85} \mathrm{Ti}_{0,15} \mathrm{Al}_{0,10} \mathrm{Ni}_{0,90}$ & 427 & 365 & $\% 86$ \\
\hline $\mathrm{Mg}_{0,80} \mathrm{Ti}_{0,20} \mathrm{Al}_{0,05} \mathrm{Zr}_{0,05} \mathrm{Ni}_{0,90}$ & 438 & 373 & $\% 85$ \\
\hline $\mathrm{Mg}_{0,85} \mathrm{Ti}_{0,15} \mathrm{Al}_{0,05} \mathrm{Ni}_{0,95}$ & 397 & 323 & $\% 81$ \\
\hline $\mathrm{Mg}_{0,85} \mathrm{Ti}_{0,10} \mathrm{Al}_{0,05} \mathrm{Ni}$ & 359 & 287 & $\% 80$ \\
\hline $\mathrm{Mg}_{0,85} \mathrm{Ti}_{0,20} \mathrm{Al}_{0,05} \mathrm{Zr}_{0,05} \mathrm{Ni}_{0,85}$ & 477 & 384 & $\% 80$ \\
\hline $\mathrm{Mg}_{0,85} \mathrm{Ti}_{0,25} \mathrm{Al}_{0,05} \mathrm{Zr}_{0,05} \mathrm{Ni}_{0,80}$ & 497 & 394 & $\% 79$ \\
\hline $\mathrm{Mg}_{0,85} \mathrm{Ti}_{0,15} \mathrm{Al}_{0,05} \mathrm{Zr}_{0,05} \mathrm{Ni}_{0,90}$ & 431 & 338 & $\% 78$ \\
\hline $\mathrm{Mg}_{0,80} \mathrm{Ti}_{0,30} \mathrm{Al}_{0,05} \mathrm{Zr}_{0,05} \mathrm{Ni}_{0,80}$ & 469 & 350 & $\% 75$ \\
\hline $\mathrm{Mg}_{0,85} \mathrm{Ti}_{0,15} \mathrm{Pd}_{0,05} \mathrm{Ni}_{0,95}$ & 382 & 285 & $\% 75$ \\
\hline $\mathrm{Mg}_{0,85} \mathrm{Ti}_{0,15} \mathrm{Zr}_{0,05} \mathrm{Ni}_{0,95}$ & 472 & 347 & $\% 74$ \\
\hline $\mathrm{Mg}_{0,85} \mathrm{Ti}_{0,15} \mathrm{Co}_{0,05} \mathrm{Ni}_{0,95}$ & 437 & 321 & $\% 73$ \\
\hline $\mathrm{Mg}_{0,85} \mathrm{Ti}_{0,10} \mathrm{Zr}_{0,05} \mathrm{Ni}$ & 387 & 276 & $\% 71$ \\
\hline $\mathrm{Mg}_{0,85} \mathrm{Ti}_{0,10} \mathrm{Pd}_{0,05} \mathrm{Ni}$ & 376 & 262 & $\% 70$ \\
\hline $\mathrm{Mg}_{0,85} \mathrm{Ti}_{0,10} \mathrm{Co}_{0,05} \mathrm{Ni}$ & 421 & 262 & $\% 62$ \\
\hline
\end{tabular}

Notten ve arkadaşları $\mathrm{Mg}_{80} \mathrm{X}_{20}(\mathrm{X}=\mathrm{Sc}, \mathrm{Ti}, \mathrm{Cr}$ ve $\mathrm{V})$ ikili elektrot alaşımını elektron ışını ile biriktirme tekniği ile kuvars alt katman üzerine ince film olarak sentezlemişlerdir. Gerçekleştirdikler

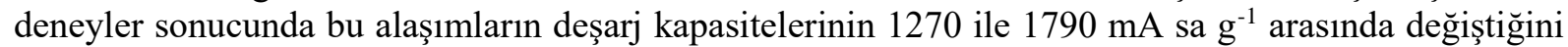
bulmuşlardır $[98,99]$. Bu alaşımlar $\mathrm{AB}_{5}$ tip hidrojen depolama alaşımlarına göre beş kat kadar daha fazla deşarj kapasitesine sahiptirler. Nanokristalin $\mathrm{Mg}_{1,95} \mathrm{Y}_{0,05} \mathrm{Ni}_{0,92} \mathrm{Al}_{0,08}$ alaşımı bir dizi sinterleme, mekanik alaşımlama ve ardından Ni ilavesi yapıldıktan sonra yapılan mekanik alaşımlama ile üretilmiştir. $\mathrm{Bu}$ alaşım mükemmel çevrim ömrüne sahiptir ve 150 çevrim sonra başlangıç kapasitesinin (385 mA sa g-1) \%96'sını koruyabilmektedir [100]. MgNi-esaslı negatif elektrot alaşımlarındaki gelişmelere rağmen bu alaşımların kararlılıkları, Magnezyumun alkalin çözelti içerisinde hızlı çözünmesinden dolayı zayıftır. Şarj edilebilir Ni-MH piller için negatif elektrot olarak MgNi esaslı metal hidrürlerin geliştirilmesi için büyük çaba sarf edilmesi gerekmektedir.

\section{Sonuç}

Bu derleme çalışmasında Ni-MH şarj edilebilir pilleri için hidrojen depolama alaşımları çeşitlerine ve bu alaşımlardaki gelişmelere değinilmiştir. Hidrojen enerjisinin önemi bu çalışmanın başlangıcında bahsedilmiş, Ni-MH şarj edilebilir pillerinin temel mekanizması anlatılmış ve Ni-MH piller için negatif elektrot olarak üretilen metal hidrür alaşımlarının kompozisyonları, mikroyapıları ve elektrokimyasal özellikleri değerlendirilmiştir.

Ancak Metal Hidrürler çeşitli dezavantajlara sahiptir. Bunlar;

1) İçeriğinde bulunan ağır metaller nedeniyle düşük kapasiteye sahiptirler.

2) Şarj/deşarj boyunca metal hidrür alaşımları şiddetli yapısal değişime uğrarlar.

3) Metal hidrürler sulu çözelti içerisinde kararlı bir yapıya sahip değildir ve yüzeyinde oluşan oksit veya hidroksit tabakası nedeniyle hidrojen depolama kapasitesi düşer.

Yapılan son çalışmalar hidrojen depolama için kullanılan alaşımların hafif metal esaslı hidrürler olması üzerine yoğunlaşmaktadır. Ancak bu alaşımların dehidrürleme termodinamik ve/veya kinetik özellikleri zayıftır. Bu nedenle çalışma sıcaklıklarında kolaylıkla bozunurlar ve çevrim kararlılıkları düşüktür. Uygulanan alaşımlama stratejileri, nano boyutlara inilmesi, katalizörler veya kompozit olarak üretim gibi hafif metal esaslı hidürür alaşımlarındaki kapsamlı gelişmeler, bu alaşımların çevrim kararlılıklarında ve şarj/deşarj kapasitelerinde istenilen düzeyde olmasını sağlayamamıştır. Bu yüzden hidrürlerin kinetik ve termodinamik özelliklerini geliştirmek için daha etkili kombinasyonal yaklaşımla gelişmeler beklenmektedir. 
Her alaşım dizaynı stratejisi metal hidrürlerin termodinamik ve kinetik özeliklerinin gelişmesinde önemli katkı sağlamaktadır. Uygun katkı maddelerinin homojen dağılımlı bir şekilde katılması, partikül boyut kontrolü ve umut verici reaktanların katılarak deneysel olarak elde edilen verilerle metal hidrürlerin termodinamik reaksiyonları için değerlendirilmesi metal hidrür alaşımlarının dizaynı için iyi bir strateji olacaktır.

Literatürde son yıllarda yapılan çalışmalarda Ti-V, R-Mg-Ni ve Mg-Ni esaslı hidrojen depolama alaşımları yüksek deşarj kapasiteleri nedeniyle oldukça dikkat çekmektedir. Ancak bu alaşımların zayıf yapısal ve çevrimsel kararlılıkları, ticari pillere göre negatif elektrot olarak üretim maliyetlerinin yüksek olması bu alaşımların Ni-MH şarj edilebilir pillerinde kullanımlarını imkansız kılmaktadır. Bu nedenle Ni-MH şarj edilebilir pilleri için negatif elektrot olarak hidrojen depolama alaşımlarının araştırılmasına ve geliştirilmesine devam edilmektedir.

\section{Kaynaklar}

[1] Zhang Y.H., Jia Z.C., Yuan Z.M., Yang T., Qi Y., Zhao D.L. 2015. Development and Application of Hydrogen Storage, International Journal of Ironand Steel, 22 (9):757-770.

[2] Lim K.L., Kazemian H., Yaakob Z., Daud W.R.W. 2010. Solid-state Materials and Methods for Hydrogen Storage: A Critacal Review, Chemical Engineering Technology, 33 (2): 213-226,

[3] Jain I.P. 2009. Hydrogen the Fuel for 21 st Century, International Journal of Hydrogen Energy, 34: 7368-7378.

[4] Aardahl C.L., Rassat S.D. 2009. Overview of Systems Considerations for On-board Chemical Hydrogen Storage, International Journal of Hydrogen Energy, 34: 6676-6683.

[5] Corgnale C., Motyka T., Greenway S. 2013. Metal Hydride Bed System Model for Renewable Source Driven Regenerative Fuel Cell, Journal of Alloys and Compounds, 580: 406-409.

[6] Wang H., Lin H.J., Cai W.T., Ouayang L.Z., Zhu M. 2016. Tuning Kinetics and Thermodynamics of Hydrogen Storage in Light Metal Element Based Systems - A review of Recent progress, Journal of Alloys and Compounds, 658: 280-300.

[7] Zacharia R., Rather S.U. 2015. Review of Solid State Hydrogen Storage Methods Adopting Different Kinds of Novel Materials, Journal of Nanomaterials, 18.

[8] Chilev C., Darkrim L. F. 2016. Hydrogen Storage at Low Temperature and High Pressure for Application in Automobile Manufacturing , International Journal of Hydrogen Energy, 41: 17441758.

[9] Sakintuna B., Lamari-Darkrim F., Hirscher M. 2007. Metal Hydride Materials for Solid Hydrogen Storage: A review, International Journal of Hydrogen Energy, 32: 1121-1140.

[10] Ouyang L., Huang J., Wang H., Liu J., Zhu M. 2017. Progress of Hydrogen Storage Alloys for Ni-MH Rechargeable Power Batteries in Electric Vehicles: A Review, Journal of Materials Chemistry, 200: 164-178.

[11] Aditya J.P., Ferdowsi M. 2008. Comparison of NiMH and Li-ion Batteries in Automotive Applications, IEEE Vehicle Power and Propulsion Conference (VPPC), 3-5 September, Harbin, China.

[12] Viswanathan B. 2017. Chapter 12- Batteries, in Energy Sources: Fundamentals of Chemical Conversion Processes and Applications Book, Elsevier, 263-313.

[13] Kleperis J.,Wojcik G., Czerwinski A., Skowronski J., KopczykM. 2001. Beltowska-Brzezinska M., Electrochemical Behavior of Metal Hydrides, Journal of Solid State Electrochemistry, 5: 229249.

[14] Liu Y.,Cao Y., Hongge P., Gao M., Wang Q. 2011. Advanced Hydrogen Storage Alloys for Ni/MH Rechargeable Batteries, Journal of Materials Chemistry, 21: 4743-4755.

[15] Feng F., Geng M., Northwood D.O. 2001. Electrochemical Behaviour of İntermetallic-based Metal Hydrides Used in Ni-Metal Hydride (MH) Batteries: A Review, International Journal of HydrogenEnergy, 26: 725-734.

[16] Cuevas F., Joubert J.M., Latroche M. 2001. Intermetallic Compounds as Negative Electrodes of Ni/MH batteries, Applied Physics A Materials, 72: 225-238. 
[17] Liu Y., Cao Y., Huang L., Gao M., Hongge P. 2011. Rareearth-Mg-Ni-based Hydrogen Storage Alloys as Negative Electrode Materials for Ni/MH Batteries, Journal of Alloys and Compounds, 509: 675- 686.

[18] Hong K. 2001. The Development of Hydrogen Storage Alloys and the Progress of Nickel Hydride Batteries, Journal of Alloys and Compounds, 321: 307-313.

[19] Iwakura C., Kajiya Y., Yoneyama H., Sakai T., Oguro K., Ishikawa H. 1989. Self-discharge Mechanism of Nickel Hydrogen Batteries Using Metal Hydride Anodes, The Electrochemical Society, 136 (5): 1351-1355.

[20] Fenga F., Northwood O. 2005.Self-discharge Characteristics of A Metal Hydride Electrode for Ni-MH Rechargeable Batteries, 30 (12):1367-1370.

[21] Tliha M., Khaldi C., Boussami S., Fenineche N., El-Kedim O., Mathlouthi H., Lamloumi J. 2014. Kinetic and Thermodynamic Studies of Hydrogen Storage Alloys as Negative Electrode Materials for Ni/MH Batteries: A Review, 18: 577-593.

[22] Notten P.H.L., Latroche M. 2009.Secondary Batteries: Nickel-Metal Hydride: Metal Hydrides, in Encyclopedia of Electrochemical Power Source, Amsterdam: Elsevier, 4: 502-521.

[23] Ratnakumart B.V., Witbam C., Bowman R.C., HightowerJr., A., Fultz B. 1996. Electrochemical Studies on LaNis-x $\mathrm{Sn}_{\mathrm{x}}$ Metal Hydride Alloys, Journal of The Electrochemical Society, 143 (8): 2578-2583.

[24] Han J.I., Lee J.-Y. 1989. Hydriding Kinetics of $\mathrm{LaNi}_{5}$ and $\mathrm{LaNi}_{4,7} \mathrm{Al}_{0,3}$, International Journal of Hydrogen Energy, 14 (3):181-186.

[25] Balogun M.-S., Wang Z.-M., Chen H.-X,Deng J.-Q, Yao Q.-R., Zhou H.-Y. 2013. Effect of Al Content on Structure and Electrochemical Properties of $\mathrm{LaNi}_{4.4-} \mathrm{Co}_{0.3} \mathrm{Mn}_{0.3} \mathrm{Al}_{\mathrm{x}}$ Hydrogen Storage Alloys, International Journal of Hydrogen Energy, 38: 10926-10931.

[26] Liu J., Yang Y., Yu P., Li Y., Shao H. 2006. Electrochemical Characterization of $\mathrm{LaNi}_{5-x} \mathrm{Al}_{\mathrm{x}}$ (x $=0.1-0.5)$ in the Absence of Additives, Journal of Power Sources, 161:1435-1442.

[27] Zhang W. 1993. Cimato J., Goudy A.J., The Hydriding and Dehydriding Kinetics of Some LaNi $i_{5}$ ${ }_{x} \mathrm{Al}_{\mathrm{x}}$ Alloys, Journal of Alloys and Compounds, 201: 175-179.

[28] Willems J.J.G., Buchow K.H.J. 1987. From Permanent Magnets to Rechargeable Hydride Electrodes, Journal of the Less-CommonMetals, 129: 13-30.

[29] Sakai T., Oguro K., Miyamura H., Kuriyama N., Kato A., Ishikawa H. 1990. Some Factors Affecting the Cycle Lives of $\mathrm{LaNi}_{5}$-based Alloy Electrodes of Hydrogen Batteries, Journal of the Less-Common Metals, 161: 193-202.

[30] Asano K., Yamazaki Y., IijimaY. 2003.Hydriding and Dehydriding Processes of $\mathrm{LaNi}_{5-\mathrm{x}} \mathrm{Co}_{\mathrm{x}}$ $(\mathrm{x}=0-2)$ Alloys Under Hydrogen Pressure of 1-5 MPa, Intermetallics 11: 911-916.

[31] Ming Q., Shuhui L., Peilin Q., Zhiqiang L., Jin G. 2011. The Influence of Co Content on LaNi $\mathrm{Li}_{3-2}$

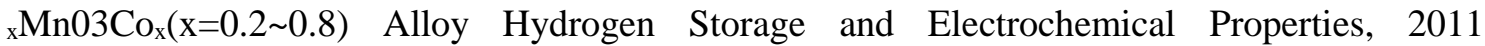
International Conference on Physics Science andTechnology (ICPST 2011), Physics Procedia 22: 577-583.

[32] Pandey S.K., Srivastava A., Srivastava O.N. 2007. Improvement in Hydrogen Storage Capacity in LaNi5 Through Substitution of Ni by Fe, International Journal of Hydrogen Energy, 32: 24612465.

[33] Young K., Ouchi T., Reichman B., Koch J., Fetcenko M.A. 2011. Improvement in the LowTemperature Performance of AB5 Metal Hydride Alloys by Fe-addition, Journal of Alloys and Compounds, 509: 7611-7617.

[34] Young K.-H., Nei J. 2013. The Current Status of Hydrogen Storage Alloy Development for Electrochemical Applications, Materials, 6: 4574-4608.

[35] Liu J., Yang Y., Li Y., Yu P., He Y., Shao H. 2007. Comparative Study of $\mathrm{LaNi}_{4.7} \mathrm{M}_{0.3}(\mathrm{M}=\mathrm{Ni}$, $\mathrm{Co}, \mathrm{Mn}, \mathrm{Al}$ ) by Powder Micro Electrode Technique, International Journal of Hydrogen Energy, 32: 1905-1910.

[36] Li S.L., Wang P., Chen W., Luo G., Han X.B., Chen D.M., Yang K. 2010. Study on Hydrogen Storage Properties of $\mathrm{LaNi}_{3.8} \mathrm{Al}_{1.2-\mathrm{x}} \mathrm{Mn}_{\mathrm{x}}$ alloys, International Journal of Hydrogen Energy, 35: 12391-12397.

[37] Borzone E.M., Blanco M.V., Baruj A., Meyer G.O. 2014. Stability of $\mathrm{LaNi}_{5-\mathrm{x}} \mathrm{Sn}_{\mathrm{x}}$ Cycled in Hydrogen, International Journal of HydrogenEnergy, 39: 8791-8796. 
[38] Ratnakumar B.V., Witbam C., Bowman R.C., Hightower Jr.-A., Fultz B .1996. Electrochemical Studies on $\mathrm{LaNi}_{5-\mathrm{x}} \mathrm{Sn}_{\mathrm{x}}$ Metal Hydride Alloys, Journal of The Electrochemical Society, 143 (8): 2578-2584.

[39] Srivastava S., Srivastava O.N. 1998. Investigations on Synthesis, Characterization and Hydrogenation Behaviour of the Spin- and Thermal-melted Versions of $\mathrm{LaNi}_{5-\mathrm{x}} \mathrm{Si}_{\mathrm{x}}(\mathrm{x}=0.1,0.3$, 0.5) Hydrogen Storage Materials, Journal of Alloys and Compounds, 267: 240-245.

[40] Adzic G.D., Johnson J.R., Reilly J.J., McBreen J., Mukerjee S., Kumar M.P.S., Zhang W., Srinivasan S. 1995. Cerium Content and Cycle Life of Multi Component $\mathrm{AB}_{5}$ Hydride Electrodes, Journal of The Electrochemical Society, 142 (10): 3429-3433.

[41] Chen J., Dou S.X., Liu H.K. 1996. Effect of Partial Substitution of La with Ce, Pr and Nd on the Properties of LaNis-based Alloy Electrodes', Journal of PowerSources, 63: 267-270.

[42] Adzic G.D., Johnson J.R., Mukerjee S., McBreen J., Reilly J.J. 1997. Function of Cobalt in $\mathrm{AB}_{5} \mathrm{H}_{\mathrm{x}}$ Electrodes, Journal of Alloys and Compounds, 253-254: 579-582.

[43] Hu W.K. 1998. Effect of Microstructure, Composition and Non-stoichiometry on Electrochemical Properties of Low-Co Rare-earth Nickel Hydrogen Storage Alloys, Journal of Alloys and Compounds, 279: 295-300.

[44] Zhang X., Chai Y., Yin W., Zhao M. 2004. Crystal Structure and Electrochemical Properties of Rare Earth Non-stoichiometric $\mathrm{AB}_{5}$-type Alloy as Negative Electrode Material in Ni-MH Battery, Journal of Solid State Chemistry ,177: 2373-2377.

[45] Zhang Y.-H., Chen M.-Y., Wang X.-L., Wang G.-Q, Lin Y.-F., Qi Y. 2004. Effect of Boron Additive on the Cycle Life of Low-Co AB 5 -type Electrode Consisting of Alloy Prepared by Cast and Rapid Quenching, Journal of Power Sources, 125, 273-279.

[46] Tang R., Zhang Z., Liu L., Liu Y., Zhu J., Yu G. 2004. Study on a Low-cobalt $\mathrm{Ml}_{0.8} \mathrm{Mg}_{0.2} \mathrm{Ni}_{3.2} \mathrm{Co}_{0.3} \mathrm{Al}_{0.3}$ Alloy, International Journal of Hydrogen Energy, 29: 851-858.

[47] Young K., Chao B., Huang B., Nei J. 2014. Studies on the Hydrogen Storage Characteristic of $\mathrm{La}_{1-\mathrm{x}} \mathrm{Ce}_{\mathrm{x}}\left(\mathrm{NiCoMnAlCuSiZr}_{5.7}\right.$ with a $\mathrm{B}_{2}$ Secondary Phase, Journal of Alloys and Compounds, 585: 760-770.

[48] Yao Q., Tang Y., Zhou H., Deng J., Wang Z., Pan S., Rao G., Zhu Q. 2014. Effect of Rapid Solidification Treatment on Structure and Electrochemical Performance of Low-Co $\mathrm{AB}_{5}$-type Hydrogen Storage Alloy, Journal of Rare Earths, 32 (6): 526-531.

[49] Wei G., Han S., Danyang X., Yuan L., Ming L., Lirong M., Lin H. 2006. Phase Structure and Electrochemical Characteristics of $\mathrm{Ml}\left(\mathrm{Ni}_{3.55} \mathrm{Co}_{0.75} \mathrm{Mn}_{0.40} \mathrm{Al}_{0.30}\right)_{5 \mathrm{x}}(\mathrm{x}=0.88,0.92,0.96,1.00)$ Hydrogen Storage Alloys, Journal of Rare Earths 24: 227-231.

[50] Jiang L., Zhan F., Bao D., Qing G., Li Y., Wei X. 1995. Low cost AB5-type Hydrogen Storage Alloys for a Nickel-Metal Hydride Battery, Journal of Alloys and Compounds 231: 635-638.

[51] Iwakura C., Ikoma K., Nohara S., Furukawa N., Inoue H. 2005. Capacity Retention Characteristics of Nickel-Metal Hydride Batteries with Polymer Hydrogel Electrolyte, Electrochemical and Solid-State Letters, 8 (1): A45-A47.

[52] Ming Q., Shuhui L., Peilin Q., Zhiqiang L., Jin G. 2011. The Influence of Co content on LaNi $i_{3.2-}$ ${ }_{x} \mathrm{Mn}_{0.3} \mathrm{Co}_{\mathrm{x}}(\mathrm{x}=0.2 \sim 0.8)$ Alloy Hydrogen Storage and Electrochemical Properties, Physics Procedia, 22: 577-583.

[53] Ozaki T.,Yang H.-B., Iwaki T., Tanase S., Sakai T., Fukunaga H., Matsumoto N., Katayama Y., Tanaka T., Kishimoto T., Kuzuhara M. 2006. Development of Mg-containing MmNis-based Alloys for Low-cost and High-power Ni-MH Battery, Journal of Alloys and Compounds, 408412: 294-300.

[54] Reilly J.J., Adzic G.D., Johnson J.R., Vogt T., Mukerjee S., McBreen J. 1990. The Correlation between Composition and Electrochemical Properties of Metal Hydride Electrodes, Journal of Alloys and Compounds, 293-295 (20): 569-582.

[55] Nakano H., Wakao S. 1995. Substitution Effect of Elements in Zr-based Alloys with Laves Phase for Nickel-Hydride Battery, Journal of Alloys and Compounds, 231: 587-593.

[56] Ulmer U., Dieterich M., Pohl A., Dittmeyer R., Linder M., Fichtner M., 2017. Study of the Structural, Thermodynamic and Cyclic Effects of Vanadium and Titanium Substitution in Lavesphase $\mathrm{AB}_{2}$ Hydrogen Storage Alloys, International Journal of Hydrogen Energy, 42 (31): 2010320110. 
[57] Matsuoka M., Tamura K. 2007. Effects of Mechanical Grinding on Initial Activation and Rate Capability of Zr-Ti Based Laves Phase Alloy Electrode, Journal Applied Electrochemistry, 37:759-764.

[58] Iwakura C., Kim I., Matsui N., Inoue H., Matsuoka M. 1995. Surface Modification of Lavesphase $\mathrm{ZrV}_{0.5} \mathrm{Mn}_{0.5} \mathrm{Ni}$ Alloy Electrodes with An Alkaline Solution Containing Potassium Borohydride as A Reducing Agent, Electrochimica Acta, 40 (5): 561-566.

[59] Gao X.P., Zhang W., Yang H.B., Song D.Y., Zhang Y.S., Zhou Z.X. 1996. Electrochemical Properties of the $\mathrm{Zr}\left(\mathrm{V}_{0.4} \mathrm{Ni}_{0.6}\right)_{2.4}$ Hydrogen Storage Alloy Electrode, Journal of Alloys and Compounds, 235: 225-231.

[60] Tan S., Shen Y., Onur Şahin E., Noreus D., Öztürk T. 2016. Activation Behavior of An $\mathrm{AB}_{2}$ type Metal Hydride Alloy for NiMH Batteries, International Journal of Hydrogen Energy, 41: 99489953.

[61] Balcerzak M. 2017. Structure and Hydrogen Storage Properties of Mechanically Alloyed Ti-V Alloys, International Journal of Hydrogen Energy, 42 (37): 23698-23707.

[62] Liu W., Kawabe Y., Liang F., Okuyama R., Lin J., Wang L. 2013. A Composite Based on Fe Substituted TiVNi Alloy: Synthesis, Structure and Electrochemical Hydrogen Storage Property, Intermetallics, 34: 18-22.

[63] Liu Y.F., Zhang S.S., Li R., Gao M.X., Zhong K., Miao H. 2008. Electrochemical Performances of the Pd-added Ti-V-based Hydrogen Storage Alloys. International Journal of Hydrogen Energy, 33: 728-734.

[64] Miao H., Gao M.X., Liu Y.F., Lin Y., Wang J.H., Pan H.G. 2007. Microstructure and Electrochemical Properties of Ti-V-based Multi Phase Hydrogen Storage Electrode Alloys $\mathrm{Ti}_{0.8} \mathrm{Zr}_{0.2} \mathrm{~V}_{2.7} \mathrm{Mn}_{0.5} \mathrm{Cr}_{0.8-\mathrm{x}} \mathrm{Ni}_{1.25} \mathrm{Fe}_{\mathrm{x}}(\mathrm{x}=0.0-0.8)$, International Journal of Hydrogen Energy, 32: 3947-3953.

[65] Tsukahara M., Takahashi K., Mishima T., Isomura A., Sakai T. 2008. Vanadium-based Solid Solution Alloys with Three Dimensional Network Structure for High Capacity Metal Hydride Electrodes, Journal of Alloys and Compounds, 253-254: 583-586.

[66] Tsukahara M., Takahashi K., Mishima T., Isomura A., Sakai T. 1996. V-based Solid Solution Alloys with Laves Phase Network: Hydrogen Absorption Properties and Microstructure, Journal of Alloys and Compounds, 236: 151-155.

[67] Tsukahara M., Takahashi K., Mishima T., Sakai T., Miyamura H., Kuriyama N. 1995. Metal Hydride Electrodes Based on Solid Solution Type Alloy $\operatorname{TiV}_{3} \mathrm{Ni}_{\mathrm{x}}(0 \leq \mathrm{x} \leq 0.75)$, Journal of Alloys and Compounds, 226: 203-207.

[68] Pan H.G., Zhu Y.F., Gao M.X., Wang Q.D. 2002. Investigation of the Structural and Electrochemical Properties of Superstoichiometric Ti-Zr-V-Mn-Cr-Ni Hydrogen Storage Alloys, Journal of The Electrochemical Society, 149(7): A829-833.

[69] Yu X.B., Wu Z., Xia B.J., Xu N.X. 2005. Electrochemical Performance of Ball-milled Ti-VBased Electrode Alloy, International Journal of Hydrogen Energy 30: 273-277.

[70] Pan H., Li R., Gao M., Liu Y., Lei Y., Wang Q. 2006. Effects of Ni on The Structural and Electrochemical Properties of Ti-V-based Hydrogen Storage Alloys, International Journal of Hydrogen Energy, 31: 1188-1195.

[71] Challet S., Latroche M., Heurtaux F. 2007. Hydrogenation Properties and Crystal Structure of the Single BCC $\left(\mathrm{Ti}_{0.355} \mathrm{~V}_{0.645}\right)_{100-\mathrm{x}} \mathrm{M}_{\mathrm{x}}$ Alloys with $\mathrm{M}=\mathrm{Mn}, \mathrm{Fe}, \mathrm{Co}, \mathrm{Ni}(\mathrm{x}=7,14$ and 21), Journal of Alloys and Compounds, 439: 294-301.

[72] Ma P., Wu E., Li W. 2014. Hydrogen Storage Properties and Microstructures of $\mathrm{Ti}_{0.7} \mathrm{Zr}_{0.3}\left(\mathrm{Mn}_{1-\mathrm{x}} \mathrm{V}_{\mathrm{x}}\right)_{2}(\mathrm{x}=0.1,0.2,0.3,0.4,0.5)$ Alloy, International Journal of Hydrogen Energy, 39 (25): 13569-13575.

[73] Mazzolai G. 2008. Some Physical Aspects of Hydrogen Behaviour in the H-Storage BCC Alloys $\mathrm{Ti}_{35} \mathrm{~V}_{\mathrm{x}} \mathrm{Cr}_{65-\mathrm{x}}, \mathrm{Ti}_{40} \mathrm{~V}_{\mathrm{x}} \mathrm{Mn}_{50-\mathrm{x}} \mathrm{Cr}_{10}$ and $\mathrm{Ti}_{\mathrm{x}} \mathrm{Cr}_{97.5-\mathrm{x}} \mathrm{Mo}_{2.5}$, International Journal of Hydrogen Energy, 33 (23): 7116-7121.

[74] Kumara S., Singh P.K., Kojima Y., Kain V. 2018. Cyclic Hydrogen Storage Properties of V-TiCr-Al alloy, International Journal of Hydrogen Energy, 43 (14): 7069-7101.

[75] Gao M., Miao H., Zhao Y., Liu Y., Pan H. 2009. Effects of Rare Earth Elements Substitution for Ti on the Structure and Electrochemical Properties of a Fe-doped Ti-V-based Hydrogen Storage Alloy, Journal of Alloys and Compounds, 484 (1-2): 249-255. 
[76] Zhang X., Sun D., Yin W., Chai Y., Zhao M. 2006. Crystallographic and Electrochemical Characteristics of $\mathrm{La}_{0.7} \mathrm{Mg}_{0.3} \mathrm{Ni}_{3.5-\mathrm{x}}\left(\mathrm{Al}_{0.5} \mathrm{Mo}_{0.5}\right)_{\mathrm{x}}(\mathrm{x}=0-0.8)$ Hydrogen Storage Alloys, Journal of Power Sources, 154: 290-297.

[77] Xiao L., Wang Y., Liu Y., Song D., Jiao L., Yuan H. 2008. Influence of Surface Treatments on Microstructure and Electrochemical Properties of $\mathrm{La}_{0.7} \mathrm{Mg}_{0.3} \mathrm{Ni}_{2.4} \mathrm{Co}_{0.6}$ Hydrogen Storage Alloy, International Journal of Hydrogen Energy, 33: 3925- 3929.

[78] Shi S., Li C., Tang W. 2009. Crystallographic and Electrochemical Performances of La-Mg-NiAl-Mo-based Alloys as Anode Materials for Nickel-Metal Hydride Batteries, Journal of Alloys and Compounds, 476: 874-877.

[79] Zhang Y.H., Dong X.-P., Wang G.-Q., Guo S.-H., Ren J.-Y., Wang X.-L. 2007. Effect of Boron Additive on Electrochemical Cycling Life of $\mathrm{La}-\mathrm{Mg}-\mathrm{Ni}$ Alloys Prepared by Casting and Rapid Quenching, International Journal of Hydrogen Energy 32: 594-599.

[80] Wang X.L., Zhang Y.H., Zhao D.L., Dong X.P., Guo S.H., Wang G.-Q. 2007. Effects of Cr Addition on the Microstructures and Electrochemical Performances of $\mathrm{La}-\mathrm{Mg}-\mathrm{Ni}$ system $\left(\mathrm{PuNi}_{3}-\right.$ type) Hydrogen Storage Alloy,Journal of Alloys and Compounds, 446-447: 625-629.

[81] Zhang Y.H., Li B. W., Ren H.P., Cai Y., Dong X.-P., Wang X.-L. 2007. Effects of Substituting $\mathrm{Ni}$ with $\mathrm{Cu}$ on the Microstructures and Electrochemical Characteristics of the As-cast and Quenched $\mathrm{La}_{0.7} \mathrm{Mg}_{0.3} \mathrm{Ni}_{2.55-\mathrm{x}} \mathrm{Co}_{0.45} \mathrm{Cu}_{\mathrm{x}}(\mathrm{x}=0.0 .4)$ Electrode Alloys, International Journal of Hydrogen Energy, 32: 3420-3426.

[82] Kadir K., Sakai T., Uehara I. 1997. Synthesis and Structure Determination of A New Series of Hydrogen Storage Alloys; $\mathrm{RMg}_{2} \mathrm{Ni}_{9}(\mathrm{R}=\mathrm{La}, \mathrm{Ce}, \mathrm{Pr}, \mathrm{Nd}, \mathrm{Sm}$ and $\mathrm{Gd})$ Built from $\mathrm{MgNi}_{2} \mathrm{Laves}$ type Layers Alternating with $\mathrm{AB}_{5}$ Layer, Journal of Alloys and Compounds, 257: 115-121.

[83] Kadir K., Sakai T., Uehara I. 1999. Structural Investigation and Hydrogen Capacity of $\mathrm{YMg}_{2} \mathrm{Ni}_{9}$ and $\left(\mathrm{Y}_{0.5} \mathrm{Ca}_{0.5}\right)(\mathrm{MgCa}) \mathrm{Ni}_{9}$ : New Phases in the $\mathrm{AB}_{2} \mathrm{C}_{9}$ System Isostructural with $\mathrm{LaMg}_{2} \mathrm{Ni}_{9}$, Journal of Alloys and Compounds, 287: 264-270.

[84] Chu H.L., Qiu S.J., Sun L.X., Zhang Y., Xu F., Jiang T., Li W.X., Zhu M., Hu W.-Y. 2007. The Improved Electrochemical Properties of Novel La-Mg-Ni-based Hydrogen Storage Composites, Electrochimica Acta, 52: 6700-6706.

[85] Zhu M., Peng C.H., Ouyang L.Z., Tong Y.Q. 2006. The Effect of Nanocrystalline Formation on the Hydrogen Storage Properties of $\mathrm{AB}_{3}$-base Ml-Mg-Ni Multi-Phase Alloys, Journal of Alloys and Compounds 426: 316-321.

[86] Qi Y.-N., Xu F., Chu H.-L., Sun L.-X., Jiang T., Zhu M. 2007. The Electrochemical Properties of $\mathrm{AB}_{3}$ /polyaniline Composites, International Journal of Hydrogen Energy, 32: 4894 - 4899.

[87] Binal Aybar A., Anik M. 2017.Direct Synthesis of La-Mg-Ni-Co type Hydrogen Storage Alloys from Oxide Mixtures, Journal of Energy Chemistry, 26 (4): 719-723.

[88] Anik M., Binal Aybar A., Küçükdeveci N., Erken H., Baksan B., Gaşan H., Hatirnaz N.B., Lökçü E. 2015. Synthesis of $\mathrm{La}_{2} \mathrm{Ni}_{7}$ Hydrogen Storage Alloy by the Electro-deoxidation Technique, International Journal of Hydrogen Energy, 40 (5): 2248-2254.

[89] Chen J., KuriyamaN., Takeshita H. T., Tanaka H., Sakai T., Haruta M. 2000. Hydrogen Storage Alloys with $\mathrm{PuNi}_{3}$-Type Structureas Metal Hydride Electrodes, Electrochemical and Solid-State Letters, 3 (6): 249-252.

[90] Zhang, F.L. Luo Y.C., Sun K., Wang D.H., Yan R.X., Kang L., Chen J.H. 2006. Structure and Electrochemical Properties of $\mathrm{La}_{2-x} \mathrm{Mg}_{x} \mathrm{Ni}_{7.0}(\mathrm{x}=0.3-0.6)$ Hydrogen Storage Alloys, Journal of Alloys and Compounds, 424: 218-224.

[91] Pan H.G., Liu Y.F., Gao M.X, Zhu Y.F., Lei Y.Q., Wang Q.D. 2003. A study on the Effect of Annealing Treatment on the Electrochemical Properties of $\mathrm{La}_{0.67} \mathrm{Mg}_{0.33} \mathrm{Ni}_{2.5} \mathrm{Co}_{0.5}$ Alloy Electrodes, International Journal of Hydrogen Energy, 28 (1):113-117.

[92] Vermeulen P.,.Niessen R.A.H, Nottena P.H.L. 2006. Hydrogen Storage in Metastable $\mathrm{Mg}_{\mathrm{y}} \mathrm{Ti}_{(1-}$ y) Thin Films, Electrochemistry Communications, 8 (1): 27-32.

[93] Huang H.X., Huang K.L., Liu S.Q., Chen D.Y. 2010. Microstructures and Electrochemical Properties of $\mathrm{Mg}_{0.9} \mathrm{Ti}_{0.1} \mathrm{Ni}_{1-\mathrm{x}} \mathrm{M}_{\mathrm{x}}(\mathrm{M}=\mathrm{Co}, \mathrm{Mn} ; \mathrm{x}=0,0.1,0.2)$ Hydrogen Storage Alloys, Powder Technology, 198 (1): 144-148.

[94] Selvam P., Viswanathan B., Swamy C.S., Srinivasan V. 1986. Magnesium and Magnesium Alloy Hydrides, International Journal of Hydrogen Energy, 11 (3): 169-192. 
[95] Cui N., Luan B., Liu H.K., Zhao H.J., Dou S.X. 1995. Characteristics of Magnesium-based Hydrogen-Storage Alloy Electrodes, Journal of Power Sources, 55 (2): 263-267.

[96] Anık M. 2010. Electrochemical Hydrogen Storage Capacities of $\mathrm{Mg}_{2} \mathrm{Ni}$ and $\mathrm{MgNi}$ Alloys Synthesized by Mechanical Alloying, Journal of Alloys and Compounds, 491 (1-2): 565-570.

[97] Anık M., Karanfil F., Küçükdeveci N. 2012. Development of the High Performance Magnesium Based Hydrogen Storage Alloy, International Journal of Hydrogen Energy, 37 (1): 299-308.

[98] NiessenaR. A. H. and Nottena P. H. L. 2005. Electrochemical Hydrogen Storage Characteristics of Thin Film MgX, X = Sc, Ti, V, Cr... Compounds, Electrochemical and Solid-State Letters, 8 (10): A534-A538.

[99] Kalisvaart W.P., Niessen R.A.H., Notten P.H.L. 2006. Electrochemical Hydrogen Storage in MgSc Alloys: A Comparative Study between Thin Films and Bulk Materials, Journal of Alloys and Compounds, 417 (1-2): 280-291.

[100] Luo J.L., Cui N., He P. 1999. Synthesis and Characterization of Nanocrystalline Magnesiumbased Hydrogen Storage Alloy Electrode Materials, Electrochimica Acta, 44: 3549-3558. 